\title{
The Role of Yeast-Surface-Display Techniques in Creating Biocatalysts for Consolidated BioProcessing
}

\author{
Ian Dominic Flormata Tabañag ${ }^{1}$, I-Ming Chu ${ }^{2}$, Yu-Hong Wei ${ }^{3}$ and Shen-Long Tsai ${ }^{1, *}$ (D) \\ 1 Department of Chemical Engineering, National Taiwan University of Science and Technology, \\ Taipei 10607, Taiwan; d10406801@mail.ntust.edu.tw \\ 2 Department of Chemical Engineering, National Tsing Hua University, Hsinchu 30013, Taiwan; \\ imchu@che.nthu.edu.tw \\ 3 Graduate School of Biotechnology and Bioengineering, Yuan Ze University, Taoyuan 32003, Taiwan; \\ yhwei@saturn.yzu.edu.tw \\ * Correspondence: stsai@mail.ntust.edu.tw; Tel.: +886-22737-6628; Fax: +886-22737-6644
}

Received: 31 January 2018; Accepted: 21 February 2018; Published: 25 February 2018

\begin{abstract}
Climate change is directly linked to the rapid depletion of our non-renewable fossil resources and has posed concerns on sustainability. Thus, imploring the need for us to shift from our fossil based economy to a sustainable bioeconomy centered on biomass utilization. The efficient bioconversion of lignocellulosic biomass (an ideal feedstock) to a platform chemical, such as bioethanol, can be achieved via the consolidated bioprocessing technology, termed yeast surface engineering, to produce yeasts that are capable of this feat. This approach has various strategies that involve the display of enzymes on the surface of yeast to degrade the lignocellulosic biomass, then metabolically convert the degraded sugars directly into ethanol, thus elevating the status of yeast from an immobilization material to a whole-cell biocatalyst. The performance of the engineered strains developed from these strategies are presented, visualized, and compared in this article to highlight the role of this technology in moving forward to our quest against climate change. Furthermore, the qualitative assessment synthesized in this work can serve as a reference material on addressing the areas of improvement of the field and on assessing the capability and potential of the different yeast surface display strategies on the efficient degradation, utilization, and ethanol production from lignocellulosic biomass.
\end{abstract}

Keywords: consolidated bioprocessing; yeast surface display; bioethanol; lignocellulosic biomass; fermentation; immobilized biocatalyst; whole-cell biocatalyst; DYSD; JANNASEY

\section{Introduction}

\subsection{Climate Change and the Bio-Based Economy}

One of the most pressing problems that the world is facing is climate change. Driven by our escalated demand of fossil-based products due to a growing population, vast amounts of greenhouse gases are released into the atmosphere; thus, inducing the greenhouse effect, which leads to global warming. The adverse effects of global warming include: long droughts, severe flooding, and even the melting of our polar ice caps. These severe changes lead to the loss of our biodiversity due to the pressure they impose on our ecosystems [1-3].

From the given scenario above, there is a need for us to shift our dependence on the current fossil-based (non-renewable) economy into a more sustainable one. This is where the bio-based economy comes in; where a lot of the energy, fuels, and products that are conventionally derived from fossil resources are produced from renewable and sustainable alternatives. The bio-based economy or bioeconomy is defined by the European Commission as "the sustainable production 
of renewable resources from land, fisheries and aquaculture environments and their conversion into food, feed, fiber bio-based products and bio-energy as well as the related public goods [2,4]". Thus, from a range of sustainable alternatives (e.g., wind, solar, geothermal, biomass, etc.) that are available, only biomass can provide us for the source of carbon that is essential for the production of tangible goods. Thus, biomass, as a sustainable resource, is the feedstock from which platform chemicals (i.e., ethanol, glycerol, butanol, propanediol, etc.) are derived and serve as a pre-cursors for the production of bio-based products (non-food products derived from biomass, such as plants, algae, crops, trees, marine organisms, and biological waste from households, animals, and food production) [3,5]. In addition, of the platform chemicals mentioned, bioethanol is easily obtained at high yields from pre-treated biomass via fermentation by certain yeasts.

\subsection{Lignocellulosic Biomass and Consolidated Bio-Processing}

The most abundant biomass (which are usually plants) found in nature, which can be used in bioethanol production via fermentation is lignocellulose, and because of its abundance, this raw material can be obtained in fact at a very low cost; it may be the best substrate with the highest potential in bioprocessing. Lignocellulose comprises $50-90 \%$ of all plant matter and it is composed of three major components, which are: cellulose, hemicellulose (which is composed mainly of xylan), and lignin. These major components of lignocellulose are in their polysaccharide forms and hydrolysis of these polysaccharides yield fermentable sugars, except for lignin (which produces phenolic compounds that actively inhibit fermentation). The major fermentable sugars produced from lignocellulose are glucose (abundant in cellulose), and xylose (abundant in hemicellulose) [6,7]. The relative concentrations of each major component is different when the plant type varies and their average concentrations are shown in Table 1.

Table 1. Components of plant lignocellulosic biomass and their typical compositions.

\begin{tabular}{ccc}
\hline Lignocellulose Component & Composition (\%) & Fermentable Sugars \\
\hline Cellulose & $\sim 35-50$ & Glucose \\
Hemicellulose & $\sim 20-35$ & Xylose, Arabinose, Mannose, Galactose \\
Lignin & $\sim 15-30$ & - \\
\hline
\end{tabular}

Direct fermentation of lignocellulosic biomass for bioethanol production is not feasible since the biomass itself is not readily fermentable by ethanol-producing microorganisms thus, expensive pre-treatment processes such as milling or steam explosion, and acid or alkaline hydrolysis are required. In the past few decades, several different strategies have been developed to produce ethanol from this kind of biomass. These strategies consists of four biologically mediated process steps, namely: (i) cellulase production, (ii) cellulose hydrolysis, (iii) hexose fermentation, and (iv) pentose fermentation. These strategies, however, require the biomass to undergo a mild pre-treatment step to disrupt its crystalline structure for the hydrolysis to proceed efficiently. In this pre-treatment step, most of the components of hemicellulose in the biomass are hydrolyzed into fermentable sugars, leaving behind cellulose in its slightly crystalline form (amorphous). Throughout the years, different processing strategies have been developed and these strategies can be categorized based on the degree to which the biologically mediated processes are consolidated. As depicted in where each process is represented as a bioreactor along with the time period when each processing strategy was developed, separate hydrolysis and fermentation (SHF) involves all the four mentioned processes discretely. Simultaneous saccharification and fermentation (SSF) consolidates cellulose hydrolysis and hexose fermentation into one step, which results in a three-step strategy. Simultaneous saccharification and co-fermentation consolidates cellulase hydrolysis and hexose-pentose fermentation which results in a two-step strategy. Finally, consolidated bioprocessing (CBP), which consolidates all process steps into a one-step bioreactor conversion strategy and schematically illustrated in Figure 1 along with the time periods where each strategy was developed [6,8-10]. 


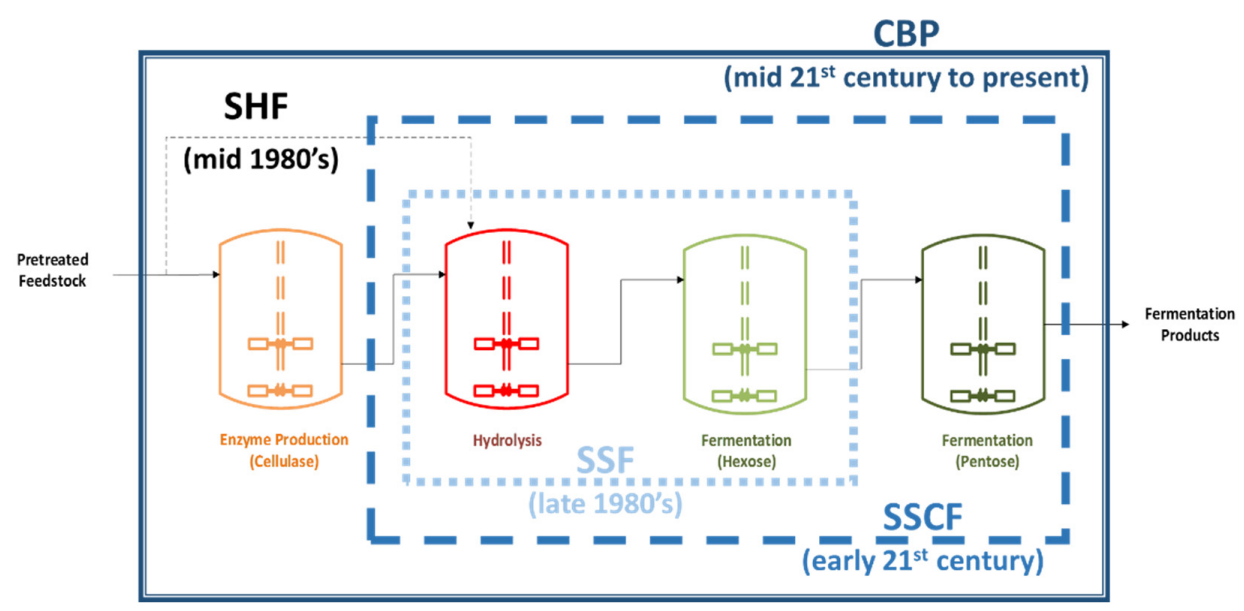

Figure 1. Schematic representation of the consolidated bioprocessing strategy.

The aim of the consolidated bioprocessing strategy is to engineer a microbial strain that is capable of producing the desired product yield by utilizing directly the pre-treated lignocellulosic biomass as a substrate via metabolic engineering (native strategy) and recombinant DNA engineering. The CBP-strategy has the potential to lower the cost of biomass processing, while producing a high-value product; this makes this strategy highly attractive and economical. The CBP-compatible microorganism of interest that has been studied extensively is the ethanologenic yeast Saccharomyces cerevisiae (which will referred as "yeast" in the following sections). However, the said yeast does not have the ability to directly use lignocellulosic biomass, although it has can produce ethanol in high yields from simple hexose sugars [6,8-10].

So, there is a need to increase the substrate utilization range of yeast for it to be able to degrade and utilize lignocellulosic biomass. This is achieved by expressing cellulose and hemicellulose degrading enzymes (cellulases, and hemicellulases, respectively) from lignocellulose degrading microorganisms in yeast and along with other metabolic pathway enzymes for the utilization of other fermentable sugars aside from glucose. The heterologous expression of the cellulases and hemicellulases in yeast will enable it to degrade these polysaccharides into fermentable sugars; then, these fermentable sugars are further converted to ethanol via the native and heterologous (for sugars other than hexoses) metabolic pathway enzymes. The following sections describe the heterologous expression of these cellulases and hemicellulases on the surface of yeast on how they improve ethanol production on lignocellulosic substrates.

\section{The Development of Yeast Cell Surface Display}

\subsection{Development of the Surface Display Technology}

Surface display systems were developed as a means to exploit the translocation of proteins on the cell surface along with their anchoring regions and apply it to heterologous proteins. In other words, this provides the idea that the cell surface is an avenue for protein immobilization, which makes it a "whole-cell biocatalyst". This system was initially demonstrated by fusing peptides to docking proteins of filamentous phage and then assembled on to the phage particle which led to the development of the "phage display system"; where it was mainly applied in high throughput screening systems using phage libraries for isolation of ligands, antibodies, etc. [11,12]. However, the limitation of the phage display system lies in the display of larger sized peptides and proteins, due to the fact the size of the fusion protein induces steric effects to the assembly of the phage particle. This limitation was then addressed by expressing the heterologous proteins fused to the surface-exposed regions of membrane proteins on the bacterial surface [13-15]. Since then, various proteins were heterologously expressed 
and localized on the bacterial surface for a wide range of applications (e.g., biosensing, bioremediation, high throughput screening, protein engineering, etc.) [16-22].

However, some heterologously expressed proteins on the bacterial surface have some limitations in expressing proteins that require post-translational modification of eukaryotic pathways, especially high molecular weight proteins from eukaryotes. Thus, the field of cell surface display was extended in yeasts (especially S. cerevisiae), which is then termed as "yeast surface display" or "yeast surface engineering". In the following sections, the term "yeast surface display" is adapted for convenience.

\subsection{Yeast Surface Display}

The potential of yeast surface display was first highlighted in the idea of an "arming technology" and its developed strains have been termed "arming yeasts" [23,24]. Furthermore, this field has elevated the status of $S$. cerevisiae as a novel and attractive microorganism to be a platform for enzyme immobilization, which enables it to target non-conventional substrates and at the same time, renewable self-immobilized biocatalysts (also known as "whole-cell biocatalysts") [24]. Its history, development, and mechanisms have been extensively discussed in the reviews of Ueda, and colleagues [25-31]. Thus, this section intends to provide a brief description on how heterologous proteins are expressed on the yeast surface in relation to CBP.

The successful expression of the heterologous proteins onto the yeast surface requires fusion to a good yeast anchor protein. An ideal anchor protein contains two essential genetic elements are required for the successful surface display of the protein of interest (POI) and these are: (i) a secretion signal sequence that mediates the transport of the POI to the cell surface where it strongly immobilizes the fused POI without interfering the activity and stability of the POI, and (ii) the glycosylphosphatidylinositol (GPI) anchor attachment signal sequence for the transient anchoring in the plasma membrane. Furthermore, a wide variety of anchor proteins are present in yeast and it is extensively described by Tanaka et al. [27,30]. Therefore, the choice of the anchor protein is thus dependent upon the characteristics of POI (e.g., location of active site, application, complex formation, etc.). In consideration of the inherent properties of the POI, the anchor protein can either be fused to either the $\mathrm{N}$ or $\mathrm{C}$ termini of the POI and Figure 2 shows on how the POI-anchor fusion is localized on the yeast surface based on the commonly utilized anchor protein systems and Table 2 shows the characteristics of the yeast anchor protein systems presented in the following sections.

(a)

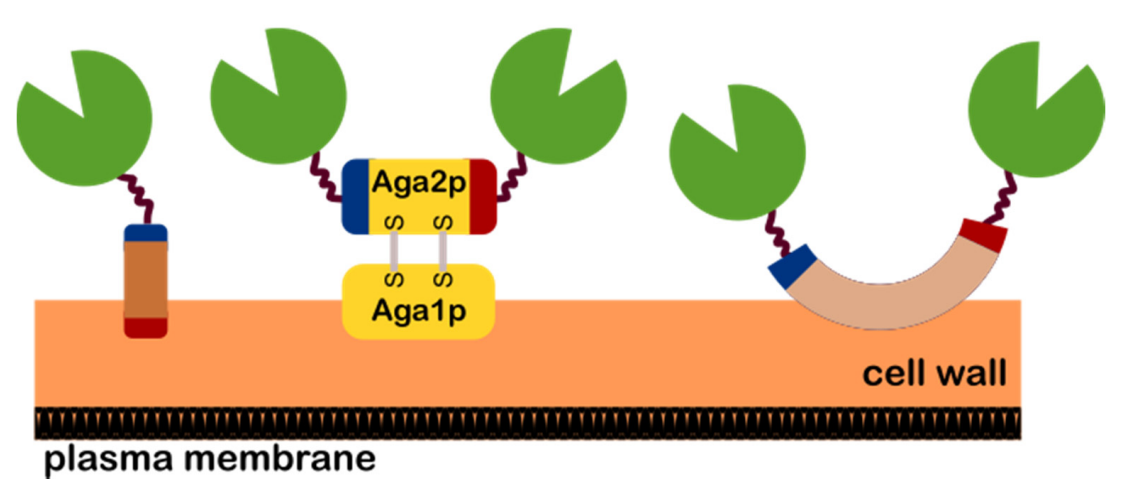

Figure 2. Common anchor protein systems used in yeast surface display: (a) N-terminal fused anchor proteins (SAG1, SED1, or CWP2); (b) the a-agglutinin display system; and, (c) the Flo1p-based display system. Anchor proteins: N-Terminal depicted in blue, and C-terminal depicted in red.

Hence, from the descriptions reported in Table 2, the anchor proteins that are mostly used for $\mathrm{N}$-terminal fusions (where the POI is fused at the $\mathrm{N}$-terminal of the anchor protein as depicted in Figure 2a) are the SAG1, SED1, and CWP2 while the a-agglutinin system is mostly used for C-terminal 
fusions (where the POI is fused at the C-terminal of the secreted AGA2 subunit as depicted in Figure $2 b$ ). In addition, several proteins have also been fused to the N-terminal (as depicted in Figure $2 b$ ) of the AGA2 subunit, which makes this system flexible in terms of the $\mathrm{N}$ or $\mathrm{C}$ terminal fusion [33]. Furthermore, the protein FLO1 (as depicted in Figure 2c) is also a flexible anchoring system where the POI can either be fused to its $\mathrm{N}$ or $\mathrm{C}$ terminal. The various truncated forms of FLO1 where its domains contain high level of $\mathrm{N}$-and $\mathrm{O}$-glycosylations provides the platform of options onto which terminal can the POI be fused [34,35]. The details of the anchor proteins utilized by the presented studies in the next sections are detailed in Table A1.

Table 2. Typical yeast anchor proteins used for surface display.

\begin{tabular}{|c|c|c|}
\hline Yeast Anchor Protein & Standard Name & Description \\
\hline$\alpha$-agglutinin & SAG1 & $\begin{array}{l}\text { Alpha-agglutinin of alpha-cells; binds to Aga1p during } \\
\text { agglutination, N-terminal half is homologous to the } \\
\text { immunoglobulin superfamily and contains binding site for } \\
\text { a-agglutinin, C-terminal half is highly glycosylated and } \\
\text { contains GPI anchor }\end{array}$ \\
\hline SED & SED1 & $\begin{array}{l}\text { Major stress-induced structural GPI-cell wall glycoprotein; } \\
\text { associates with translating ribosomes, possible role in } \\
\text { mitochondrial genome maintenance }\end{array}$ \\
\hline Cwp2 & CWP2 & $\begin{array}{l}\text { Covalently linked cell wall mannoprotein; major constituent } \\
\text { of the cell wall; plays a role in stabilizing the cell wall; } \\
\text { involved in low pH resistance; precursor is GPI-anchored }\end{array}$ \\
\hline Flo428p & FLO1 & $\begin{array}{l}\text { Lectin-like protein involved in flocculation; cell wall protein } \\
\text { that binds mannose chains on the surface of other cells, } \\
\text { confers floc-forming ability that is chymotrypsin sensitive } \\
\text { and heat resistant; important for co-flocculation with other } \\
\text { yeasts, mediating interaction with specific species }\end{array}$ \\
\hline \multirow{2}{*}{ a-agglutinin system } & AGA1 & $\begin{array}{l}\text { Anchorage subunit of a-agglutinin of a-cells; highly } \\
\text { O-glycosylated protein with N-terminal secretion signal and } \\
\text { C-terminal signal for addition of GPI anchor to cell wall, } \\
\text { linked to adhesion subunit Aga2p via two disulfide bonds }\end{array}$ \\
\hline & AGA2 & $\begin{array}{l}\text { Adhesion subunit of a-agglutinin of a-cells; C-terminal } \\
\text { sequence acts as a ligand for alpha-agglutinin (Sag1p) } \\
\text { during agglutination, modified with O-linked } \\
\text { oligomannosyl chains, linked to anchorage subunit Aga1p } \\
\text { via two disulfide bonds }\end{array}$ \\
\hline
\end{tabular}

Data obtained from SGD Project. http:/ /www.yeastgenome.org [32].

\subsection{Strategies for the Yeast Surface Display of CBP-Related Enzymes}

The different strategies for the immobilization of cellulases and hemicellulases utilized in the studies presented in the next section are shown in Figure 3.

Due to the complex structure of lignocellulose in lignocellulosic biomass, it is a given that different types of enzymes are required to break down the polysaccharides into the fermentable monosaccharide sugars that the yeast can transport and utilize. Thus, these different types of enzymes are to be displayed on the yeast surface to provide a synergistic effect when it comes to the degradation of lignocellulose. The advantage of expressing multiple-enzymes on the surface of yeast is that the yeast cells are capable of direct degradation and utilization of lignocellulosic substrates in situ. In other words, it combines the enzyme production, immobilization, and metabolic degradation steps in a one-pot setting; a fitting platform for CBP. The description and classification of the strategies shown in Figure 3 are as follows: 
1. Direct Yeast Surface Display (DYSD) —-this strategy directly involves the fusion of the enzyme of interest/s to the yeast anchor protein for it to be expressed and localize on its surface and is further classified into the following:

a. $\quad$ Single enzyme display consortium (SEDC)—a mixed culture (a.k.a synthetic consortium) strategy of different strains with each displaying one type of enzyme. The utilization of the mixed culture technique is adapted as a means to control the multi-enzyme composition or ratios via the culture inoculation ratios.

b. Co-display (CD) - the direct display of more than one enzymes on yeast that is achieved by directly cloning the enzyme/s fused with anchor protein into one yeast strain. The control of the displayed enzyme ratios

2. Juxtaposed Assembly of Non-Native Adaptors and Secreted Enzymes on Yeast (JANNASEY) - this strategy is developed based on the biomimicry of the "cellulosome" machinery of several anaerobic cellulose-consuming microorganisms (e.g., clostridia, ruminal bacteria) [36,37]. In addition, exploiting the cellulosome's nature as a reconfigurable platform for immobilization of multiple enzymes including an enzyme cascade configuration, along with the advancement of molecular biology and conjugation techniques, led to the creation of "designer cellulosomes". These designer cellulosomes typically consists of the cell wall anchoring subunit (or sometimes directly fused to the adaptor subunit) for cell wall attachment, the adaptor subunit (a.k.a. scaffoldin or miniscaffoldin), which consists of the configurable multi-cohesin along with the cellulose binding domains that either bind to the anchoring subunit or onto another adaptor subunit, and finally the secreted enzyme subunit which consists of enzyme/s each fused to a specific dockerin domain that corresponds to the cohesin/s in the adaptor subunit [38]. The term "minicellulosomes" is often used to distinguish the designer cellulosomes that contain engineered adaptor subunits (a.k.a. miniscaffoldin to be consistent with the minicellulosome) with non-native cohesin and cellulose-binding domains. Other researchers' even use the term "truncated cellulosome" that is synonymous to the minicellulosome to even give it a clearer distinction with the cellulosome [37,39]. In order to prevent the inappropriate use of the terms related to cellulosomes in this article, this yeast display strategy is generally classified as the juxtaposed assembly of non-native adaptors and secretion enzymes on yeast in reference to its structured and precise self-assembly on yeast. Furthermore, the various assembly techniques of the cellulosome components are classified as follows:

a. Single multi-functional adaptor assembly (SMFAA) — this strategy typically involves the consortium of two sets of strains wherein one strain displays the chimeric adaptor subunit on its surface, and another set of strains that secrete the dockerin fused enzymes that assemble in situ onto the displayed adaptor subunit of another strain. The multi-functionality this system is derived from the fact that the adaptor subunit it contains varying cohesin domains from different microorganisms for specificity.

b. Complex adaptor assembly (CAA) — this is a direct biomimicry of the native bacterial cellulosome assembly where one or more adaptor subunits are assembled on the bacterial surface. When applied to yeast surface display, it involves a consortium of at least three sets of strains where one strain displays the anchoring subunit, another set of strains that secrete one or more adaptor subunits (one of which binds to the anchoring subunit and another type of binds to the cell-surface-anchored adaptor), and finally the strains that secrete the dockerin fused enzymes, which assemble onto the adaptors. The complex assembly is regulated by the valence (monovalent if it contains a single cohesin and polyvalent if it contains more than one) of the adaptor subunit. Adaptor polyvalence can also be achieved by specifically engineering the adaptor to contain multiple cohesin types from different microorganisms for regulating the enzyme loading via cohesin-dockerin specificity. 


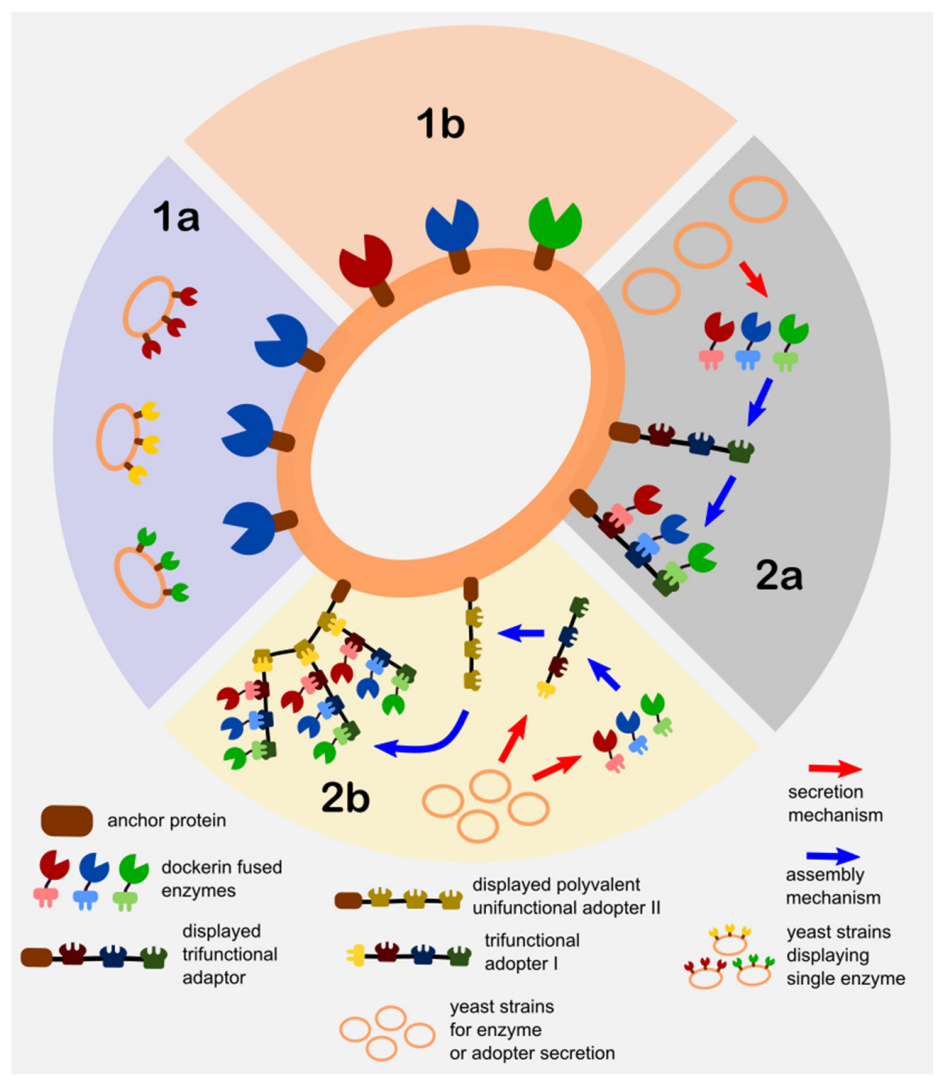

Figure 3. Cellulase and Hemicellulase Surface display strategies for Consolidated BioProcessing. (1a) DYSD-SEDC, (1b) DYSD-CD, (2a) JANNASEY-SMFAA, (2b) JANNASEY-CAA.

\section{Yeast Surface Display Studies for Bioethanol Production from Lignocellulosic Biomass}

The selected studies presented in this section are those that have applied the yeast surface display system in ethanol fermentation from lignocellulosic substrates. These studies are classified into the ethanol fermentation of: pure cellulose, pure hemicellulose, and pre-treated lignocellulosic biomass substrates. The purpose of this is to differentiate between the systems that utilize pure polysaccharide substrates from actual pre-treated plant substrates. Furthermore, these studies are compared with each other based on the following fermentation parameters: (i) Ethanol titer, (ii) Substrate type, and (iii) Ethanol substrate conversion yield. The ethanol substrate conversion yield (ESCY, \%) is defined as the amount of ethanol titer obtained with respect to theoretical ethanol produced from the total fermentable sugars in the substrate and is operationally defined in Equation (1).

$$
\operatorname{ESCY}(\%)=\frac{C_{\mathrm{EtOH}}^{\text {titer }}}{C_{\text {substrate }} \times X_{\mathrm{TFS}} \times Y_{\mathrm{PS}}^{\text {theo }}} \times 100
$$

where: ESCY-Ethanol Substrate Conversion Yield; $C_{\mathrm{EtOH}}^{\text {titer }}$ - ethanol titer; $C_{\text {substrate }}$-substrate concentration; $X_{\mathrm{TFS}}-$ composition of total fermentable sugars in the substrate; $Y_{\mathrm{PS}}^{\text {theo }}$ - theoretical ethanol yield from monosaccharides (typically $\sim 0.51 \mathrm{~g}$ ethanol per $\mathrm{g}$ sugar).

Prior to looking into the ethanol performance of yeast surface display in the following sections, it should be noted that the advantage of employing the yeast surface display system lies in the fact that it either retains or increases the overall enzymatic activity upon the immobilization of the enzyme/s of interest on its surface when compared to its free enzyme (enzyme in solution) counterpart. This is discussed in the following paragraph.

In most of the cases, yeast surface display performance can be assessed by comparing the normalized enzymatic activities (expressed in terms of activity units with respect to the amount 
of cells secreting/displaying the said enzymes) for both the secreted and displayed configuration of the enzyme of interest. Specifically in the context of this review, the enzymatic activity refers to the rate release of sugars (e.g., total reducing sugars (TRS), or a specific sugar being assayed). Additionally, for the cases when multiple enzymes are employed, the parameter utilized for the assessment of the multi-enzymatic performance would be the "degree of synergy". The degree of synergy is defined as "the ratio of the rate or yield of product released by enzymes when used together to the sum of the rate or yield of these products when the enzymes are used separately in the same amounts as they were employed in the mixture $[40,41] "$. In other words, this refers to the ratio of the mixture activity to its theoretical mixture activity (sum of individual mixture activities). In the context of lignocellulosic bioethanol production, this refers to the amount of fermentable sugars hydrolyzed by an enzyme mixture with respect to its theoretical mixture hydrolysis activity.

It has been demonstrated that the application of yeast surface display to the enzymes (i.e., cellulases, hemicellulases) relevant to lignocellulosic bioethanol production has exhibited improved hydrolytic activities with respect to their free enzyme counterparts. In addition, enhancement in the degree of synergy was observed when mixtures of the said surface displayed enzymes (i.e., cellulases, hemicellulases) were utilized for substrate hydrolysis [42-46].

Thus, in terms of industrial relevance, yeast surface display provides a platform where enzyme/s are both produced and self-immobilized on its surface (creating a whole-cell biocatalyst platform) in a manner where the activities of the enzyme/s are retained as long as there is continuous growth of yeast in the fermentation process. Another feature of this system lies in the ease of separation of the whole-cell biocatalyst from the fermentation media, which enables the reusability of yeast cells. The reusability of the yeast cells as whole cell biocatalysts takes advantage of the fact that the enzymes displayed on its surface are active upon reuse; this translate to cost reduction for yeast propagation or enzyme addition [24,47].

\subsection{Pure Cellulose Substrates}

The predominant component of lignocellulosic biomass is cellulose and it serves as its main structural component. It consists of glucose chains linked via $\beta-1,4$ linkages and this chains are linked together by strong hydrogen bonding that forms the cellulose chains into microfibrils making it crystalline in nature, and thus recalcitrant to degradation; although some parts of the cellulose structure are easier to degrade due to its amorphous configuration. These structural variabilities (crystalline and variable regions) in the cellulose structure make it at least partially hydrated by water when immersed in aqueous media and along with some micropores and capillaries, it provides enough space for some enzymes, such as cellulases to penetrate. Cellulose is produced mainly by delignification of wood or other plant biomass materials. The pure celluloses utilized for hydrolysis studies vary considerably in fine structural features and the choice of substrate can affect the hydrolysis itself. Microcrystalline celluloses are nearly pure cellulose and a dilute-acid treatment step is typically utilized in their preparation, which results in the removal of hemicelluloses and amorphous regions of the cellulose fibers. Furthermore, commercial microcrystalline cellulose differ primarily on size distribution has significant implications for the rate of hydrolysis and utilization, as discussed in the studies presented in this subsection. In addition, the varying structural complexity (in terms of crystallinity) of pure cellulose and the difficulty of its insolubility has led to the wide use of a highly soluble cellulose ether, carboxymethylcellulose (CMC), which is chemically synthesized by the alkali-catalyzed reaction of cellulose with chloroacetic acid [6,8,48-50].

In general, the degradation of cellulose into glucose requires at least three types of enzymes (cellulases). These are typically: endocellulases (randomly cleave internal bonds at amorphous sites that create new chain ends), exocellulases (which includes cellobiohydrolases (CBH) and cleave two to four units from the ends of the exposed chains produced by endocellulase, resulting in tetrasaccharides or disaccharides, such as cellobiose), and cellobioases (a.k.a $\beta$-glucosidases, hydrolyse the exocellulase product into individual monosaccharides; specifically cellobiose) $[6,7]$. The action 
of these cellulases on cellulose are schematically illustrated in Figure 4. Basically, the cellulose chains are efficiently degraded into soluble cellooligosaccharides and cellobiose by the endo and exocellulases, and then further hydrolyzed into glucose by the $\beta$-glucosidase. The studies presented in this subsection have exploited the different yeast surface display strategies for cellulases, which created recombinant yeasts that produce cellulosic ethanol. Furthermore, synergistic interactions between cellulases have been reported to occur between: different exocellulases (with specificity for reducing and non-reducing ends), endo, and exocellulases, between different endocellulases, and between endocellulases and $\beta$-glucosidases [51-56]. Additionally, high cellulase synergy has been observed on the hydrolysis of highly crystalline cellulose substrates when compared to the more amorphous cellulose [53,57].

In conjunction with the different cellulases utilized along with the yeast surface display system, the commonly exploited synergistic interactions for cellulosic bioethanol production are the interactions between endo and exocellulases, and endocellulases and $\beta$-glucosidases; as these two synergistic interactions are significant to the efficient glucose release from the cellulose structure. This configuration can produce whole-cell biocatalysts that can directly degrade cellulose and potentially produce high ethanol yields from the glucose released from the cellulose structure.

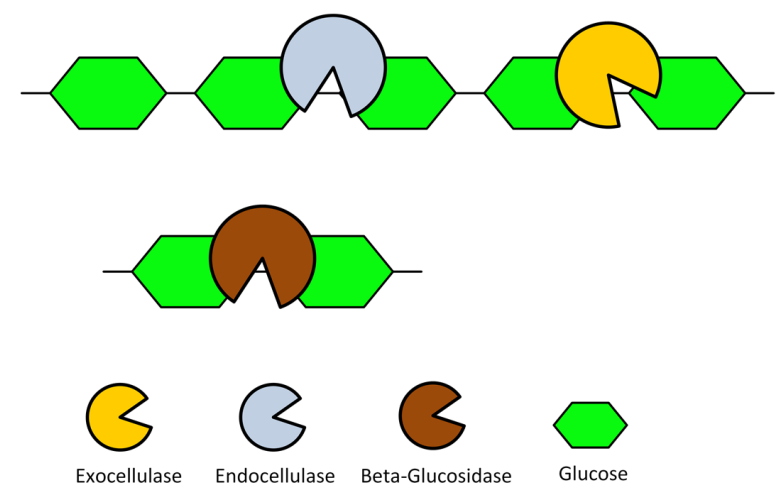

Figure 4. Basic structural component of cellulose and the cellulases responsible for its degradation.

\subsubsection{DYSD Strategy for Cellulosic Bioethanol Fermentation}

The first reported attempt to convert the cellulosic barley $\beta$-glucan into ethanol was described by Fujita, et al. [58]; where the Trichoderma reesei endoglucanase II (EGII) and Aspergillus aculeatus $\beta$-glucosidase (BGL1) were co-displayed on the yeast surface. The resulting strain has performed efficient simultaneous saccharification and fermentation of cellulose to ethanol by producing $\sim 17 \mathrm{~g} / \mathrm{L}$ ethanol in $48 \mathrm{~h}$ from $45 \mathrm{~g} / \mathrm{L} \beta$-glucan with an ethanol substrate conversion yield (ESCY) of $~ 74 \%$. Then, this yeast strain was further modified by adding the T. reesei cellobiohydrolase II (an exoglucanase, CBHII) and tested on phosphoric acid cellulose (PASC). This modified strain has produced $3 \mathrm{~g} / \mathrm{L}$ of ethanol in $40 \mathrm{~h}$ with an ESCY of $\sim 61 \%$ from $10 \mathrm{~g} / \mathrm{L}$ PASC [59]. Furthermore, Kotaka, et al. [60] have co-displayed both an endoglucanase (CelB) and a $\beta$-glucosidase (BGL-B7) from Aspergillus oryzae on the cell surface of an industrial sake yeast and successfully produced ethanol $\sim 8 \mathrm{~g} / \mathrm{L}$ ethanol in $24 \mathrm{~h}$ with an ESCY of $\sim 70 \%$ from $20 \mathrm{~g} / \mathrm{L} \beta$-glucan. Interestingly, Liu, et al. [61] has demonstrated different combined approaches of yeast surface-display and secretion strategies. With the main premise that the $\beta$-glucosidase is displayed on the yeast surface to facilitate in the efficient transport of glucose upon the degradation of cellobiose. Their findings suggest that placing endoglucanase (EG) and cellobiohydrolase (CBHI) in the same space (on the cell surface or in the medium) was favorable for amorphous cellulose-based (PASC) ethanol fermentation; while the cellulolytic yeast strain that produced enzymes by the cell-surface display strategy performed better in cell-recycle batch fermentation compared to strains producing enzymes via the secretion strategy. Based on the highest obtained parameters, the system has produced $\sim 3 \mathrm{~g} / \mathrm{L}$ ethanol in $96 \mathrm{~h}$ with an ESCY of $\sim 60 \%$ from 
$10 \mathrm{~g} / \mathrm{L}$ PASC [61]. In another study by the same research group [62], two exoglucanases from Talaromyces emersonii and Chrysosporium lucknowense, a T. reesei endoglucanase (EG2), and an A. aculeatus $\beta$-glucosidase (BGL1) were co-displayed on the yeast surface to create a novel cellulose adherent yeast strain. When assessed on the non-treated (Avicel) and acid-treated (PASC) cellulose, the strain exhibited clear cell to cellulose adhesion and a tearing (almost ubiquitous pattern when compared to the layer by layer action by free cellulases) cellulose degradation pattern; adhesion ability correlated with enhance surface area and roughness of cellulose fibers resulting in higher hydrolysis efficiency. The obtained parameters from both substrates are: $\sim 2 \mathrm{~g} / \mathrm{L}$ ethanol in $96 \mathrm{~h}$ with an ESCY of $\sim 30 \%$, and $\sim 7 \mathrm{~g} / \mathrm{L}$ ethanol in $96 \mathrm{~h}$ with an ESCY of $\sim 68 \%$, from $10 \mathrm{~g} / \mathrm{L}$ Avicel and $20 \mathrm{~g} / \mathrm{L}$ PASC, respectively [63].

In the degradation of lignocellulosic substrates, the biochemical composition of the substrate dictates the cocktail of enzymes that is required for its efficient hydrolysis. Because of this, one of the major limitations of the direct surface display strategies is the control of the ratio or the composition of the different enzymes being displayed on the yeast surface However, this limitation was overcome through controlling the expression levels of the different enzymes using the novel cocktail delta-integration approach introduced by Yamada, et al. [64,65]. The expression levels of the different enzymes was directly controlled by the gene copy numbers of the different enzymes when integrated into the multiple delta-sites (a long-term terminal repeat, LTR, component of the retrotransposable Ty elements) that are present in the yeast genome. Then this enzyme expression control strategy was applied by Yamada, et al. [66], in the co-display of the T.reesei endoglucanase II (EGII) and cellobiohydrolase II (CBHII), along with the A. aculeatus $\beta$-glucosidase (BGL1) on the yeast cell surface and have successfully obtained $\sim 3 \mathrm{~g} / \mathrm{L}$ ethanol in $72 \mathrm{~h}$ with and ESCY of $\sim 31 \%$ from $20 \mathrm{~g} / \mathrm{L}$ PASC. When the same co-display system was introduced into a diploid yeast strain, the parameters obtained were improved (almost thrice as much) when compared to the co-display system of the haploid yeast strain; specifically $\sim 8 \mathrm{~g} / \mathrm{L}$ ethanol in $72 \mathrm{~h}$ with an ESCY of $\sim 77 \%$. This was a first demonstration that the utilization of a recombinant diploid strain is an improvement to the ethanol fermentation capacity from cellulosic biomass when compared to its haploid counterpart [66]. A similar control strategy was adapted by Apiwatanapiwat, et al. [67] in the co-display of five (5) different (two amylases, two cellulases, and one $\beta$-glucosidase) enzymes on the yeast surface. The resulting strain was designed for the ethanol fermentation from cassava pulp (which mainly contains starch and cellulosic fibre). When tested with the cellulosic substrates PASC ( $\sim \mathrm{g} / \mathrm{L}$, total sugar), and $\beta$-glucan $(\sim 10 \mathrm{~g} / \mathrm{L}$, total sugar), the obtained fermentation parameters ethanol titer, fermentation time, and ESCY were $1.1 \mathrm{~g} / \mathrm{L}$, within $24 \mathrm{~h}, \sim 25 \%$, and $5.3 \mathrm{~g} / \mathrm{L}, 36 \mathrm{~h}, 97 \%$, respectively [67]. In an attempt to improve the efficient utilization of cellulose hydrolysis products, Yamada, et al. [68] adapted the same control strategy and cellulase co-display system, while in this case, the $\beta$-glucosidase was expressed intracellularly along with the Neurospora crassa cellodextrin transporter (cdt1) The expression of the cellodextrin transporter along with the intracellular $\beta$-glucosidase will enable the resulting yeast strain to efficiently transport the cellobiose produced during cellulose hydrolysis into the cell and intracellularly degrade it into glucose then convert it to ethanol. When the resulting strain was assessed by ethanol fermentation from $20 \mathrm{~g} / \mathrm{L}$ PASC, it has successfully obtained $4.3 \mathrm{~g} / \mathrm{L}$ ethanol in $72 \mathrm{~h}$ with an ESCY of $\sim 44 \%$ where the titer was about 1.7 times higher when compared to the strain not expressing the cellodextrin utilization pathway [68]. Another case where two exoglucanases from T. emersonii and C. lucknowense, a T. reesei endoglucanase (EG2), and an A. aculeatus $\beta$-glucosidase (BGL1) were co-displayed using the cocktail delta-integration strategy on the yeast surface by Liu, et al. [69] in the attempt to obtain a highly cellulolytic strain. The transformants were then subjected to a high-throughput screening (HTS) methodology for the selection of the strain that exhibits high cellulolytic activity. The resulting strain that exhibits the highest cellulolytic activity was subjected to ethanol fermentation from Avicel (non-treated crystalline cellulose) and it obtained $\sim 3 \mathrm{~g} / \mathrm{L}$ of ethanol within $96 \mathrm{~h}$ with an ESCY of $\sim 60 \%$ (highest reported ethanol yield for from avicel) [69].

An alternative technique of controlling the ratio or the composition of surface displayed enzymes in a mixture for cellulose degradation and utilization was to utilize a consortium of strains where 
different types of strains display one type of cellulase per strain was introduced by Baek, et al. [45]. Control was achieved by adjusting the inoculation ratios of each strain displaying the $T$. reesei cellobiohydrolase II (CBHII), Thermoascus aurantiacus endoglucanase I (EGI), and the A. aculeatus $\beta$-glucosidase (BGLI). Different inoculation ratios were investigated and the resulting formulation that exhibits the highest cellulolytic activities were assessed for ethanol fermentation from $10 \mathrm{~g} / \mathrm{L}$ PASC and obtained $\sim 2.1 \mathrm{~g} / \mathrm{L}$ ethanol in $85 \mathrm{~h}$ with an ESCY of $\sim 43 \%$ [45].

\subsubsection{JANNASEY Strategy for Cellulosic Bioethanol Fermentation}

The successful assembly of multi-functional cellulosomes on the yeast surface were described by Ito, et al. [70] and Lilly, et al. [71]. Tsai, et al. [46] then assessed the ethanol fermentation from $10 \mathrm{~g} / \mathrm{L}$ PASC of a yeast strain with a pre-assembled minicellulosome (the dockerin-fused enzyme subunits were expressed and purified in E. coli before its assembly on the yeast strain displaying the configurable adaptor/miniscaffoldin subunit) that displays Clostridium cellulolyticum exoglucanase (CelE), both Clostridium thermocellum endoglucanase (CelA) and $\beta$-glucosidase (BglA). The pre-assembled minicellulosome-displaying strain has produced $\sim 4 \mathrm{~g} / \mathrm{L}$ ethanol in $50 \mathrm{~h}$, with an ESCY of $~ 71 \%$ from PASC [46]. In the endeavor to assemble the minicellulosome in situ, the same research group of Tsai, et al. [72] adapted a yeast consortium strategy, which consists of two sets of yeast strains where minicellulosome assembly is achieved via intracellular complementation (i.e., one set of strains displaying adaptor subunit, while another set of strains secretes the three cellulases, CelE, CelA, and BglA onto the adaptor-displaying strains). Different inoculation ratios of the two sets of strains were investigated and the resulting consortium were screened based on their overall cellulolytic activities and ethanol production from PASC. The optimized consortium produced $\sim 2 \mathrm{~g} / \mathrm{L}$ ethanol in $70 \mathrm{~h}$ with an ESCY of $\sim 40 \%$ [72]. Another case of utilizing a multi-functional cellulosome system was demonstrated by Wen, et al. [73], where the native adaptor/scaffoldin subunits derived from $C$. thermocellum (CipA1, for the co-display of three uni-functional minicellulosomes and CipA3, for the co-display of a tri-functional minicellulosome) were exploited to produce two minicellulosome display schemes. The cellulases displayed on these minicellulosome schemes were both the T. reesei endoglucanase II (EGII), and cellobiohydrolase II (CBHII), along with the A. aculeatus $\beta$-glucosidase (BGLI). The resulting display scheme that exhibited the highest parameters among them was the one displaying the tri-functional minicellulosome. The obtained parameters were $1.8 \mathrm{~g} / \mathrm{L}$ ethanol in $70 \mathrm{~h}$ with an ESCY of $\sim 37 \%$ from $10 \mathrm{~g} / \mathrm{L}$ PASC [73]. In another endeavor to achieve efficient cellulose hydrolysis using by exploiting the native adaptor subunit of C. thermocellum (mini-CipA), Kim, et al. [74] designed a yeast consortium strategy that consists of three sets of strains where two of which is involved in the intracellular complementation minicellulosome assembly (one strain set displays the mini-CipA adaptor subunit while another set secretes the dockerin-fused enzyme subunits), and the third set directly displays the A. aculeatus $\beta$-glucosidase (BGLI). The resulting consortium is a combination of the minicellulosome assembled C. thermocellum endoglucanase (CelA), and the T. reesei cellobiohydrolase II (CBHII), along with the strain displaying the BGL1. The inoculation ratios of the four different yeast populations were optimized based on the rational design and screening methods adapted from Baek, et al. [45]; where ethanol production optimization was directly based on changing the population inoculation ratios of the different strain sets. The resulting optimized inoculation ratio did produce $\sim 2 \mathrm{~g} / \mathrm{L}$ ethanol in $94 \mathrm{~h}$ with an ESCY of $\sim 38 \%$ from $10 \mathrm{~g} / \mathrm{L}$ PASC where the titer was 1.2 times higher when compared to an 1:1 (equal) ratio of the three strain sets [74].

One of the limitations of the single multi-functional adaptor cellulosome assembly is on limited number of enzymes (enzyme loading) displayed on the single adaptor platform. This limitation can be overcome by using multiple adaptors that mimic the native bacterial (e.g., Ruminococcus flavefaciens) complex cellulosome machinery where it involves the utilization of polyvalent adaptors (either with multiple cohesin domains from one strain, or from multiple strains) [38]. Fan, et al. [75] demonstrated this complex assembly using two different adaptor subunits. Specifically, these adaptor subunits are: (i) the tri-functional chimeric (which contains three cohesin domains from different species and a 
dockerin domain for binding on to the adaptor subunit II) trivalent adaptor subunit I that displays the C. cellulolyticum endoglucanase(CelCCA), cellobiohydrolase (CelCCE), and $\beta$-glucosidase (Ccel_2454) fused to different dockerin domains, (ii) the polyvalent adaptor subunit II that contains more than one cohesin domains that bind to the corresponding dockerin domain on the adaptor subunit I and at the same time displayed on the yeast surface. This complex assembly permits the display of more than one adaptor subunit I with the displayed cellulases on the adaptor subunit II thus increases the amount of cellulases displayed (enhanced enzyme loading) on the yeast surface. In addition, the adaptor subunit I and the cellulases were expressed and purified in Escherichia coli, and then assembled on the yeast displaying the adaptor subunit II. The resulting complex cellulosome assembly was then tested for ethanol production from non-treated (Avicel) and acid-treated (PASC) cellulose. Obtained fermentation parameters are $\sim 1.4 \mathrm{~g} / \mathrm{L}$ ethanol in $96 \mathrm{~h}$ with an ESCY of $\sim 29 \%$, and $\sim 1.1 \mathrm{~g} / \mathrm{L}$ ethanol in $96 \mathrm{~h}$ with and ESCY of $\sim 22 \%$, from $10 \mathrm{~g} / \mathrm{L}$ of Avicel and PASC respectively. The difference in fermentation performance between Avicel and PASC substrate systems was attributed to the enhanced accessibility that is offered by the Avicel structure to the complex cellulosome assembly. In other words, the complex cellulosome prefers being bound to the non-treated substrate [75]. A similar approach in the complex cellulosome assembly was also demonstrated by Tsai, et al. [76]. In this case however, the adaptor subunits are specifically designed to contain chimeric cohesins which leads to a tetravalent designer cellulosome assembly. The adaptor subunits designed are as follows: (i) a bivalent bifunctional adaptor subunit I which contains two chimeric scaffoldins and at the same time displayed on the yeast surface, (ii) two variants of the bivalent bifunctional adaptor subunit II (due to the two different dockerin domains fused to each of the adaptor subunits that bind to the corresponding cohesins on the adaptor subunit I) which displays the C. cellulolyticum endoglucanase (CelG), and the C. thermocellum $\beta$-glucosidase (BGL1), fused with two different chimeric dockerin domains that bind on the respective chimeric cohesins. Similarly, the two variants of the adaptor subunit II along with the cellulases were expressed and purified in E. coli and then assembled on the yeast displaying the adaptor subunit I and the resulting assembly was tested for ethanol fermentation from PASC. The system has produced $\sim 2 \mathrm{~g} / \mathrm{L}$ ethanol in $72 \mathrm{~h}$ with an ESCY of $\sim 40 \%$. This tetravalent assembly exhibited a $\sim 2$-fold higher ethanol production when compared to the bivalent assembly system. This result indicates a direct relationship between enzyme loading and ethanol production capacity [76]. In an endeavor to enhance cellulose hydrolysis and utilization, Fan, et al. [77] has integrated their complex cellulosome assembly strategy [75], along with the cellodextrin utilization pathway. In this case, the adaptor subunit I in this case was bi-functional and at the same time displays the T. reesei cellobiohydrolase II (CBHII), and the C. cellulolyticum endoglucanase (EGII) The tetravalent adaptor subunit II, which contains four cohesin domains, was displayed on the surface of yeast. The N. crassa cellodextrin transporter (cdt1) along a $\beta$-glucosidase (gh1-1) were expressed intracellularly. Furthermore, the cellodextrin utilization pathway and the adaptor subunits were co-expressed in yeast, thus enabling the resulting strain for the co-fermentation of cellulose and galactose (the purpose of galactose is for the co-induction and expression of the adaptor subunits); and the complex cellulosome assembles in situ. The strain was then tested for its ability to produce ethanol acid treated cellulose (PASC) and the soluble carboxymethylcellulose (CMC). The obtained fermentation parameters are $\sim 1.1 \mathrm{~g} / \mathrm{L}$ ethanol in $60 \mathrm{~h}$ with an ESCY of $\sim 22 \%$, and $\sim 3.3 \mathrm{~g} / \mathrm{L}$ ethanol in $60 \mathrm{~h}$ with an ESCY of $\sim 66 \%$, for $10 \mathrm{~g} / \mathrm{L}$ PASC and $10 \mathrm{~g} / \mathrm{L} \mathrm{CMC}$, respectively (both are mixed with $20 \mathrm{~g} / \mathrm{L}$ galactose). Moreover, the advantage of this co-expression system is that the resulting fermentation setup only requires a small inoculation of the non-induced yeast cells to efficiently convert both cellulose and galactose to ethanol in a single-step co-fermentation process [77].

\subsection{Pure Hemicellulose Substrates}

As the second most abundant polysaccharide in lignocellulosic biomass, efficient enzymatic degradation of hemicellulose is quite challenging due to its complex biochemical structure. In general, hemicellulose is a hetero-polysaccharide that is composed of different sugar units 
(the commercially important sugar units are: xylose, mannose, galactose, arabinose, and rhamnose). As a hetero-polysaccharide, it has various polysaccharide forms depending on the biomass feedstock (i.e., wood, plants and plant gum, and agricultural waste), the major hemicelluloses being xylans, mannans, arabinans, and galactans [78]. The most common hemicellulose that is found in lignocellulosic biomass from agricultural waste (e.g., sugar cane bagasse, sugar beet pulp, rice and wheat straw, cornstalk, and cobs) is xylan [79]. The xylan structure relevant enzymes for its degradation are illustrated in Figure 5 [80]. In other words, the xylan side-chains are removed via the action of the accessory enzymes to produce linear xylose chains then cleaved into soluble xylooligosaccharides and xylobiose via the action of the endoxylanase and finally releasing xylose via the action of $\beta$-xylosidase. These hemicellulases can be then exploited along with yeast surface display to produce whole-cell biocatalysts for xylan degradation. Also, it was generally reported that accessory enzymes, such as xylan esterases, arabinofuranosidases, glucuronidases, and mannases synergistically enhances the main-chain cleaving enzymes (i.e., xylanases, xylosidases) in the release of xylose from pure hemicellulose substrates, such as wheat arabinoxylan, oat-spelt, beechwood, and birchwood xylans [81-85]. Though it should be noted that not all hemicellulase combinations would lead to a positive synergism between them. Some exhibit negative synergism (also referred as anti-synergism) in cases when one of the enzymes in the mixture inhibits the action of its other constituents [86]. Furthermore, some cases show that some accessory enzymes exhibit no synergy with respect to the main-chain cleaving enzymes; in other words, the addition of the accessory enzyme did not even improve the xylose, arabinose, mannose, or ferulic acid release, either due to the nature of the enzyme (e.g., substrate specificity, reaction conditions, etc.) or the complexity of the substrate [82,87-89].

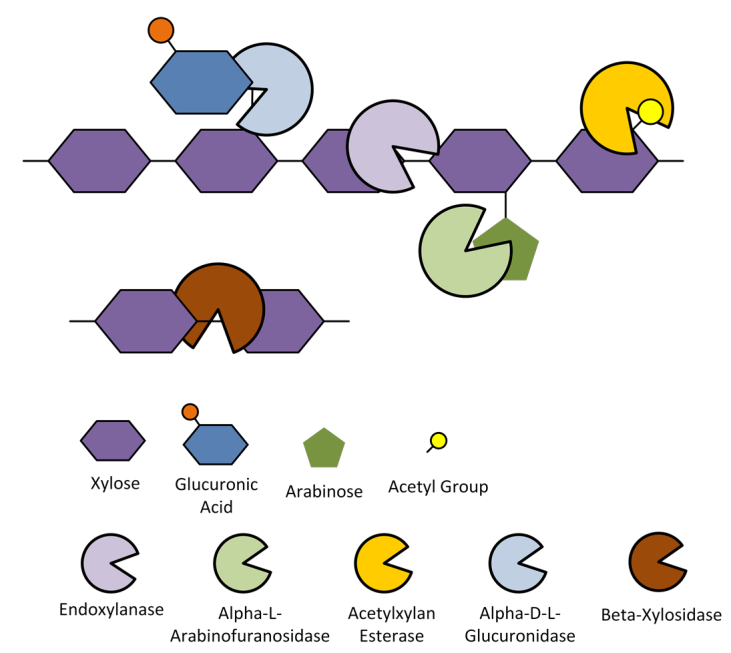

Figure 5. Basic structural component of xylan and the hemicellulases required for the efficient release of xylose from its structure.

On the other hand, another of the most challenging conundrums to use S. cerevisiae in CBP is the inability of $S$. cerevisiae to completely break down hemicellulose due to its structural complexity and to utilize the pentose sugars (e.g., xylose) released upon hemicellulose degradation. This drawback is especially relevant for ethanol fermentation from hemicellulosic feedstock. The efforts in metabolic engineering of S. cerevisiae has enabled this yeast to utilize xylose and convert to ethanol via two heterologous metabolic pathways. The first developed xylose utilization pathway in yeast (termed $\mathrm{XR}-\mathrm{XDH}$ pathway) involves the conversion of xylose to xylitol by a xylose reductase (XR), xylitol is then converted into xylulose by a xylose dehydrogenase $(\mathrm{XDH})$, then xylulose is further processed via the pentose-phosphate (PP), and the glycolysis (Embden-Meyerhoff-Parnas, EMP) pathways to produce ethanol [90]. The second developed xylose utilization pathway (termed as the XI or XI-XK pathway) in yeast completely bypasses the xylitol formation by directly converting xylose into xylulose 
by a xylose isomerase (XI) enzyme, then further converted to ethanol; a novel pathway derived from anaerobic ruminant bacteria [91-94].

Therefore, the combination of the hemicellulase expression, xylose utilization pathways, has generated recombinant yeast strains that directly produce ethanol from xylan substrates. So far, only a few studies regarding hemicellulosic ethanol production via yeast surface display technologies have been performed. Nonetheless, the studies in this subsection have extended the yeast surface display technologies motivated by the developments in cellulosic ethanol production.

\subsubsection{DYSD Strategy for Hemicellulosic Bioethanol Fermentation}

Katahira, et al. [95] first demonstrated the construction of a recombinant yeast strain that is capable of producing ethanol from xylan. The heterologous XR-XDH pathway derived from P. stipitis was expressed in their previously developed yeast strain that co-displays the T. reesei xylanase II (XYNII) and the A. oryzae a $\beta$-xylosidase (XylA) [96]. The resulting strain was then assessed for its ability to produce ethanol from $100 \mathrm{~g} / \mathrm{L}$ of birchwood xylan and has obtained $\sim 7 \mathrm{~g} / \mathrm{L}$ ethanol in $62 \mathrm{~h}$ with an ESCY of $16 \%$.

The endeavor to utilize five T. reesei hemicellulases, namely xylanase II (Xyn2), $\beta$-xylosidase (Bx11), arabinofuranosidase (Abf1), $\alpha$-D-glucurunidase (Glr1), and acetylxylan esterase (Axe1); that efficiently release xylose from the basic xylan structure described in Figure 5 and convert it to ethanol was explored by Tabañag and Tsai [42] upon investigating the synergistic interactions between the five hemicellulases during xylan hydrolysis. These five hemicellulases were then individually displayed on the yeast surface co-expressed along with the XI-XK pathway xylose utilization enzymes derived from Prevotella ruminicola where each resulting strain can utilize xylose and display one hemicellulase on its surface. The optimum hemicellulase formulations were obtained from the hemicellulase synergy experiments for xylan hydrolysis using the mixture experimental design methodology. The xylan fermentation setup involves a synthetic consortium of these five stains and hemicellulase formulation was controlled by setting up the inoculation ratios/compositions of each strain adapted from Baek, et al. $[45,74]$. This synthetic consortium system was assessed for its ethanol production from two xylan substrates and the obtained fermentation parameters are, $\sim \mathrm{g} / \mathrm{L}$ ethanol in $168 \mathrm{~h}$ with an ESCY of $\sim 23 \%$, and $\sim 0.8 \mathrm{~g} / \mathrm{L}$ ethanol in $168 \mathrm{~h}$ with an ESCY of $\sim 30 \%$, from $10 \mathrm{~g} / \mathrm{L}$ of beechwood xylan, and wheat arabinoxylan, respectively [42]. This was a demonstration that the xylose released by the synthetic consortium-surface display system was utilized and converted to ethanol via the application of a minimal metabolic engineering approach for xylose utilization.

In another case of hemicellulose degradation, Ishii, et al. [43] focused on the degradation and utilization of mannan using the surface display technology. Mannan, a type of hemicellulose where at its basic structure consists of mannose linked together in a linear fashion (similar to cellulose in both polysaccharide structure and insolubility in water). Furthermore, the mannanases responsible for mannan degradation have similar functions with their cellulase counterparts. Specifically, $\beta$-mannanases are the pivotal enzymes that initiate mannan degradation by randomly cleaving the mannan backbone to liberate short manno-oligomers and produce new chain ends, the $\beta$-mannosidases which are exo-acting enzymes responsible for the hydrolysis of non-reducing terminal ends and mano-oligomers thus liberating mannose [97]. Unlike xylose, which requires a heterologous metabolic pathway utilization, mannose is inherently utilized by yeast and directly converted to ethanol, thus requiring no further metabolic engineering for mannose utilization. Thus, by co-displaying the $A$. aculeatus $\beta$-mannanase (Man5A) and $\beta$-mannosidase (Mnd2A), the resulting yeast strain was able to directly convert mannan to ethanol. The obtained fermentation parameters are $\sim 10 \mathrm{~g} / \mathrm{L}$ of ethanol in $312 \mathrm{~h}$ with an ESCY of $\sim 23 \%$ from $100 \mathrm{~g} / \mathrm{L}$ of $\beta$-D-mannan.

\subsubsection{JANNASEY Strategy for Hemicellulosic Bioethanol Fermentation}

Though the application of the surface display adaptor assembly for hemicellulosic ethanol is limited, it is quite relevant that this type of surface display strategy was explored for this type of 
substrate. Srikrishnan, et al. [44] demonstrated the assembly of a minixylanosome (a counterpart of the minicellulosome) on yeast. This assembly consists of a trivalent tri-functional adaptor subunit that is attached on the surface of yeast where three hemicellulases fused with different dockerin domains: the Thermomyces lanuginosus endoxylanases (XynA), Aspergillus niger $\beta$-xylosidase (XylA), and the Aspergillus awamori acetylxylan esterase (AXE) assemble and display onto. The resulting minixylanosome assembly performed $\sim 3.3$ times better (with respect to the degree of synergy) in the hydrolysis of birchwood xylan when compared to their free hemicellulase mixture counterpart. Moreover, their results highlighted the significance of hemicellulase positioning in the minixylanosome assembly in relation to the substrate channeling phenomenon (defined as the coupling of two or more enzymatic reactions, in which the common intermediate is transferred in between the enzymes without escaping to the bulk phase that avoids side reactions or protects the unstable intermediate [98]) [44].

In terms of direct xylan utilization in yeast, Sun, et al. [99] demonstrated the assembly of a single bifunctional minixylanosome in combination with the heterologous XR-XDH xylose utilization pathway derived from $P$. stipitis. The assembly consists of a bivalent adaptor subunit (CipA3) from C. thermocellum attached to the yeast surface that displays the T. reesei endoxylanase II (Xyn2) and A. niger $\beta$-xylosidase (XylA) fused with the corresponding dockerin domains. Both the adaptor subunit and the secreted subunits were co-expressed along with the XR-XDH pathway enzymes in one yeast strain and the minixylanosome assembly occurred in situ. The resulting strain that displays the bifunctional minixylanosome assembly was able to directly produce ethanol from xylan. The obtained fermentation parameters are $\sim 1 \mathrm{~g} / \mathrm{L}$ ethanol in $80 \mathrm{~h}$ with an ESCY of $\sim 21 \%$. In addition, the repeated batch fermentation of the mannanase displaying yeast showed ability to produce ethanol in three cycles. Furthermore, recovered yeast after the 1st batch fermentation exhibited high manannase activities from the early fermentation stages of the succeeding cycles, which supports the hypothesis that high activities were due to the relevantly expressed mannanases on the yeast surface [99].

\subsection{Pre-Treated Lignocellulosic Substrates}

Lignocellulosic biomass is considered as a second generation feedstock; given the conditions that it does not compete with the food supply, has a low-value (or no value), and in abundant supply. The feedstock that fulfills these conditions involve inedible plant materials. This involves agricultural waste (e.g., rice straw, corn stover and cob, bagasse, molasses), forestry wastes (e.g., wood chips), municipal and industrial waste (e.g., used paper), and fast growing energy crops (e.g., switch grass, miscanthus) [100]. Due to its complex lignocellulosic biomass structure, a certain degree of pre-treatment is involved to liberate its polysaccharide components (i.e., cellulose, hemicellulose, and lignin) prior to the bioprocessing steps. In addition, it should be noted that during the pre-treatment process, a certain extent of fermentable sugars are already released from its polysaccharide structure, depending on the severity of the pre-treatment step. Furthermore, the most common substrate that is presented in this subsection is rice straw, which has undergone liquid hot water pre-treatment (a.k.a. autohydrolysis or hydrothermolesis). For this type of pre-treatment, $\sim 50 \%$ of the total biomass is dissolved in the process, with $6-22 \%$ of cellulose, $30-60 \%$ of the lignin, and the removal of all hemicelluloses. More than $\sim 90 \%$ of the hemicelluloses are degraded into its monomeric sugars when an acid is utilized to hydrolyze the resulting liquid. Though the results of this pre-treatment step vary with the biomass type due to the high lignin solubilization that impedes the recovery of hemicellulose sugars [78,100-102]. Moreover, for the direct utilization of pre-treated lignocellulosic substrates, the presented studies in this subsection so far have reported the application of the direct yeast surface display strategy (DYSD).

\section{DYSD Strategy for Bioethanol Fermentation from Pre-Treated Lignocellulosic Biomass}

Yamada, et al. [66] has first demonstrated the ethanol production from agricultural waste biomass using the engineered cellulase co-displaying diploid yeast without the addition of exogenous enzymes, as presented in Section 3.1.1. When assessed for its ethanol production from pre-treated 
rice straw, the engineered yeast has obtained $\sim 8 \mathrm{~g} / \mathrm{L}$ ethanol in $72 \mathrm{~h}$ with an ESCY of $\sim 36.47 \%$ from $100 \mathrm{~g} / \mathrm{L}$ of pre-treated rice straw [66]. In an attempt to improve the ethanol substrate conversion yield from pre-treated rice straw, Matano, et al. [103] has investigated the supplementation of exogenous commercial cellulases (Cellulase SS) to yeast co-displaying the T. reesei endoglucanase (EGII) and cellobiohydrolase (CBHII), along with the A. aculeatus $\beta$-glucosidase (BGL1). This strategy successfully reduced the amount of commercial enzyme required for the fermentation of cellulose as the ethanol production performance of the cellulase co-displaying yeast supplemented with $10 \mathrm{FPU} / \mathrm{g}$ biomass .cellulases was comparable to the system that consists of a control yeast strain (no display) supplemented with $100 \mathrm{FPU} / \mathrm{g}$ biomass cellulase. These results demonstrate that cellulases displayed on the yeast cell surface are capable of hydrolyzing cellulose that was not hydrolyzed by commercial cellulases, leading to increased sugar utilization for improved ethanol production. The obtained fermentation parameters for the system consisting the cellulase co-displaying yeast supplemented with $10 \mathrm{FPU} / \mathrm{g}$ biomass of cellulase are $\sim 43 \mathrm{~g} / \mathrm{L}$ ethanol in $72 \mathrm{~h}$ with an ESCY of $\sim 90 \%$ [103]. Then this engineered strain was tested for its performance in a cell batch recycle fermentation (CRBF) setup [104]. For five (5) repeated fermentation cycles, the cells displaying cellulases [103] were recycled and assessed using the same pre-treated rice straw substrate. With five consecutive recycling cycles, ethanol fermentation parameters was maintained all throughout and obtained $\sim 42 \mathrm{~g} / \mathrm{L}$ ethanol in the total $360 \mathrm{~h}$ (five cycles) with an ESCY of $\sim 86 \%$. This was a first demonstration of the utilization of CRBF with cellulase displaying cells. Indeed, the results suggest that the these cells retained their hydrolysis and ethanol production activities when exposed to five consecutive fermentation cycles [104]. In a succeeding study by Sakamoto, et al. [105], the xylose utilization from the pre-treated rice straw was investigated. The XR-XDH pathway xylose utilization enzymes from P. stipitis were co-expressed with the two hemicellulases and one cellulase, T. reesei endoxylanase II (Xyn2), A. oryzae $\beta$-xylosidase (XylA), and $A$. aculeatus $\beta$-glucosidase (BGL1), co-displayed on the yeast surface. When assessed for ethanol production from pre-treated rice straw, the obtained fermentation parameters are $\sim 8 \mathrm{~g} / \mathrm{L}$ ethanol in $72 \mathrm{~h}$ with a reported ethanol yield of $\sim 82 \%$ (based from the sugars consumed) [105]. Another study by Liu, et al. [62], as described and presented in Section 3.1.1, have assessed the performance of their novel adherent yeast strain co-displaying four cellulases on pre-treated rice straw. The obtained fermentation parameters are $\sim 1.3 \mathrm{~g} / \mathrm{L}$ of ethanol in $96 \mathrm{~h}$ with an ESCY of $\sim 7 \%$ from $100 \mathrm{~g} / \mathrm{L}$ of rice straw hydrolysate. The fermentation performance was then improved by supplementing $1 \mathrm{FPU} / \mathrm{g}$ biomass of commercial cellulase (Ctec2) to the novel adherent yeast strain and the system has produced $\sim 18 \mathrm{~g} / \mathrm{L}$ of ethanol in $96 \mathrm{~h}$ with an ESCY of $\sim 91 \%$ from $100 \mathrm{~g} / \mathrm{L}$ of the same substrate. This cellulase supplemented system has the achieved the same ethanol fermentation performance when compared to the control system (non-cellulase displaying yeast with cellulase addition) provided the $40 \%$ decrease in commercial cellulase dosage [62]. In another study of the same research group, Liu, et al. [69], which has combined the cellulase ratio optimization with novel high throughput screening (HTS) methodology (as described and presented in Section 3.1.1), have assessed the ethanol fermentation performance of resulting strain from pre-treated rice straw. The fermentation parameters obtained by this strain are $\sim 1 \mathrm{~g} / \mathrm{L}$ ethanol in $96 \mathrm{~h}$ with an ESCY of $\sim 17 \%$. This strain has performed $\sim 2.5$ times better than the one previously reported [62] in terms of ethanol substrate conversion. These results demonstrated the potential of the novel high-throughput screening methodology in improving the performance of the engineered strain via tuning the cellulase ratios in the yeast co-display strategy [69]. From another perspective, Guirimand, et al. [106] have explored the direct utilization of pre-treated rice straw and convert it to xylitol. By co-expressing the P. stipitis xylose reductase (XR) enzyme along with the T. reesei endoxylanase II (Xyn2), A. oryzae $\beta$-xylosidase (XylA), and A. aculeatus $\beta$-glucosidase (BGL1), co-displayed on the yeast surface. They have assessed the ethanol performance of this strain on pre-treated rice straw. The resulting strain has produced $\sim 6 \mathrm{~g} / \mathrm{L}$ xylitol in $96 \mathrm{~h}$ with a xylitol substrate conversion yield (XSCY) of $\sim 47 \%$ from the total xylose present in the $500 \mathrm{~g} / \mathrm{L}$ of rice straw hydrolysate. In an effort to increase xylitol yield by increasing the xylose or xylose oligomer concentration in the hydrolysate, an additional membrane filtration step was introduced and this step 
significantly concentrated the sugars in the hydrolysate, while drastically reducing the fermentation inhibitor concentrations. The obtained xylitol performance parameters of the developed strain on this substrate are $\sim 38 \mathrm{~g} / \mathrm{L}$ xylitol in $96 \mathrm{~h}$ with a XSCY of $\sim 65 \%$ from the total xylose present in $500 \mathrm{~g} / \mathrm{L}$ filtered hydrolysate. These results demonstrate that the additional filtration step has enabled the strain to perform $~ 1.4$ times better in the filtered hydrolysate when compared to the unfiltered one; showing that increased xylose utilization was attributed to the removal of fermentation inhibitors after filtration [106].

Bioethanol production from other pre-treated lignocellulosic substrates, such as wood chips, cassava pulp, and ivory nut were also explored and presented in the next paragraph.

Katahira, et al. [107] have investigated the xylose and cellobiose utilization in acid-treated wood chips. The XR-XDH xylose utilization pathway enzymes from $P$. stipitis were co-expressed with the A. aculeatus $\beta$-glucosidase (BGL1) displayed on the yeast surface. This resulting strain was then assed for its ethanol production from wood chip hydrolysate (with $\sim 72 \mathrm{~g} / \mathrm{L}$ total sugar concentration) and has produced $\sim 30.3 \mathrm{~g} / \mathrm{L}$ ethanol in $36 \mathrm{~h}$ with an ESCY of $\sim 82 \%$. Furthermore, the fermentation of the wood chip hydrolysate was similar to the mixed sugar fermentation model system, which suggests that the inhibitory effects of some of the hydrolysate components does not exhibit significant inhibition to the engineered strain [107]. Apiwatanapiwat, et al. [67] has tested their amylase-cellulase co-displaying yeast strain, as described and presented in Section 3.1.1 in liquid hot water pre-treated cassava pulp. The fermentation parameters obtained by this strain are $\sim 10 \mathrm{~g} / \mathrm{L}$ ethanol in $48 \mathrm{~h}$ with an ESCY of $\sim 80 \%$ from $50 \mathrm{~g} / \mathrm{L}$ pre-treated cassava pulp; demonstrating the ability of the strain to directly utilize starch and cellulose present in the medium [67]. Ishii, et al. [43], whose research group has explored on the direct mannan degradation by mannanase displaying yeast strains, as described and presented in Section 3.1.1, have extended the scope of lignocellulosic biomass utilization to mannan derived from ivory nuts. The ivory nut mannan was subjected to alkaline hydrolysis prior to fermentation. When the engineered strain displaying mannanases were assessed for their ethanol fermentation performance from this substrate, it has obtained $\sim 10 \mathrm{~g} / \mathrm{L}$ ethanol in $216 \mathrm{~h}$ with an ESCY of $\sim 20 \%$ from $100 \mathrm{~g} / \mathrm{L}$ of ivory nut mannan [43].

\subsection{Comparing the Various Yeast Surface Display Strategies for Bioethanol Fermentation from Lignocellulosic Biomass Substrates}

The fermentation parameters from the different studies presented in this subsection were compared with respect to their different display strategies, and substrate types. These different data types are incorporated and then visualized via bubble charts. By no means does the comparison presented in the bubble charts for the following sub-subsections imply the suitability of a certain surface display strategy to ethanol conversion yield for that type of substrate. It is just a means to visualize the state and progress of yeast surface display technology in bioethanol production from lignocellulosic substrates. In other words, these charts serve as an aid in comparing the performances of the cell-surface engineered strains provided the type of surface display strategy being adapted, and the type of substrate being utilized since the superiority of the different yeast surface technologies were by far already demonstrated in comparison to their free enzyme counterparts.

The data visualized in the bubble charts are presented in a way that the ethanol substrate conversion yield (ESCY) values are plotted in a chronological order such that the progress and development of yeast surface display for lignocellulosic bioethanol production can be directly seen. The ESCY vs time series is then augmented by the ethanol titer as represented by the bubble sizes or circle areas to show how much ethanol was produced from the given substrate that corresponds to its ESCY. The corresponding data labels basically provides the information on the substrate types and their corresponding concentrations in the fermentation media. 


\subsubsection{Cellulosic Bioethanol Fermentation}

In terms of bioethanol production from lignocellulosic biomass, the widely utilized and tested substrate is the pure cellulose substrates since the yeast $S$. cerevisiae is an ethanologenic yeast strain that can produce high amounts of ethanol from glucose, once liberated from the cellulose structure. Thus, in most cases, the various yeast surface display strategies that are presented throughout this article were first explored in the direct utilization of pure cellulose substrates, and then extended to pre-treated lignocellulosic biomass, prior to its application to direct hemicellulose utilization.

The comparison of the different studies presented in Section 3.1 are visualized in Figure 6. Looking at the capability to convert half of the expected ethanol from the substrate (ESCY of $>50 \%$ ), it can be generalized that direct co-display (DSYD-CD) of cellulases performed well given that the substrates are acid (PASC) and alkali (BBglucan) pre-treated, and solubilized (CMC). Furthermore, using the delta-integration strategy to control the cellulase co-display ratio has provided an insight to the importance of cellulase display optimization and strain improvement by diploidization $[66,67,69]$. It can also be observed that the ESCY performance on the utilization of glucan is better than that of cellulose (either treated or non-treated) substrates, and this can be attributed to their structures where cellulose has a more rigid structure (more crystalline) than glucan. One can also notice that most non-treated cellulose (Avicel) were utilized as substrates for the complex adaptor assembly systems (JANNASEY-CAA), which address the enzyme loading limitation of DSYD systems though the obtained conversion yields were mostly $<50 \%$.

\subsubsection{Hemicelllulosic Bioethanol Fermentation}

The application of yeast surface display technology in hemicellulosic ethanol production demonstrates its potential for efficient lignocellulosic biomass utilization. Though the presented studies report ethanol substrate conversion yields of $\sim 16-30 \%$, as visualized in Figure 7 , it has shown that direct conversion of pure hemicellulose substrates like xylan and mannan to ethanol is achievable. These reported studies have gradually filled the gap in the field of hemicellulosic bioethanol fermentation. In terms of efficient xylan hydrolysis by hemicellulases, the direct yeast surface display system (DYSD-SEDC) by Tabañag and Tsai [42] achieved 23-30\% ethanol substrate conversion yields from different xylan substrates, which highlights the significance of different hemicellulase synergistic interactions for the efficient xylose release from the xylan structure. In addition, the utilization of surface display strategies also exhibited superior performance in terms of xylan hydrolysis with respect to their free hemicellulase counterparts.

So far, the attempt to assess the efficiency of these surface display strategies remain a challenge since this field is not that elaborate when compared to the advances in cellulosic bioethanol production. At least it can be stressed out that for xylan degradation and utilization, the combination of the efficient xylan degradation by hemicellulases and the improved xylose utilization are both avenues that warrant further investigation.

\subsubsection{Bioethanol Fermentation from Pre-Treated Lignocellulosic Biomass}

From the description presented in Section 3.3 that upon pre-treatment, a certain extent of fermentable sugars are already being released to the medium, thus, in principle these sugars are readily available for direct utilization by the yeast cells. As visualized in Figure 8, this explains the high amounts of ethanol titer (in reference to the large circle areas) that are obtained from pre-treated lignocellulosic biomass substrates. The low yields, however, are related to the high substrate loadings ( $\sim 100 \mathrm{~g} / \mathrm{L})$ that directly correspond to the amount of oligosaccharides present in the medium along that require hydrolysis by the engineered yeast strain displaying the necessary enzymes or to the action of exogenous commercial enzymes added to supplement the hydrolysis process prior to the release of fermentable sugars $[43,62,66,69]$; or to the presence of fermentation inhibitors that can be removed via an additional process step (i.e., membrane filtration) [106]. 
- DYSD-SEDC • DYSD-CD • JANNASEY-SMFAA • JANNASEY-CAA

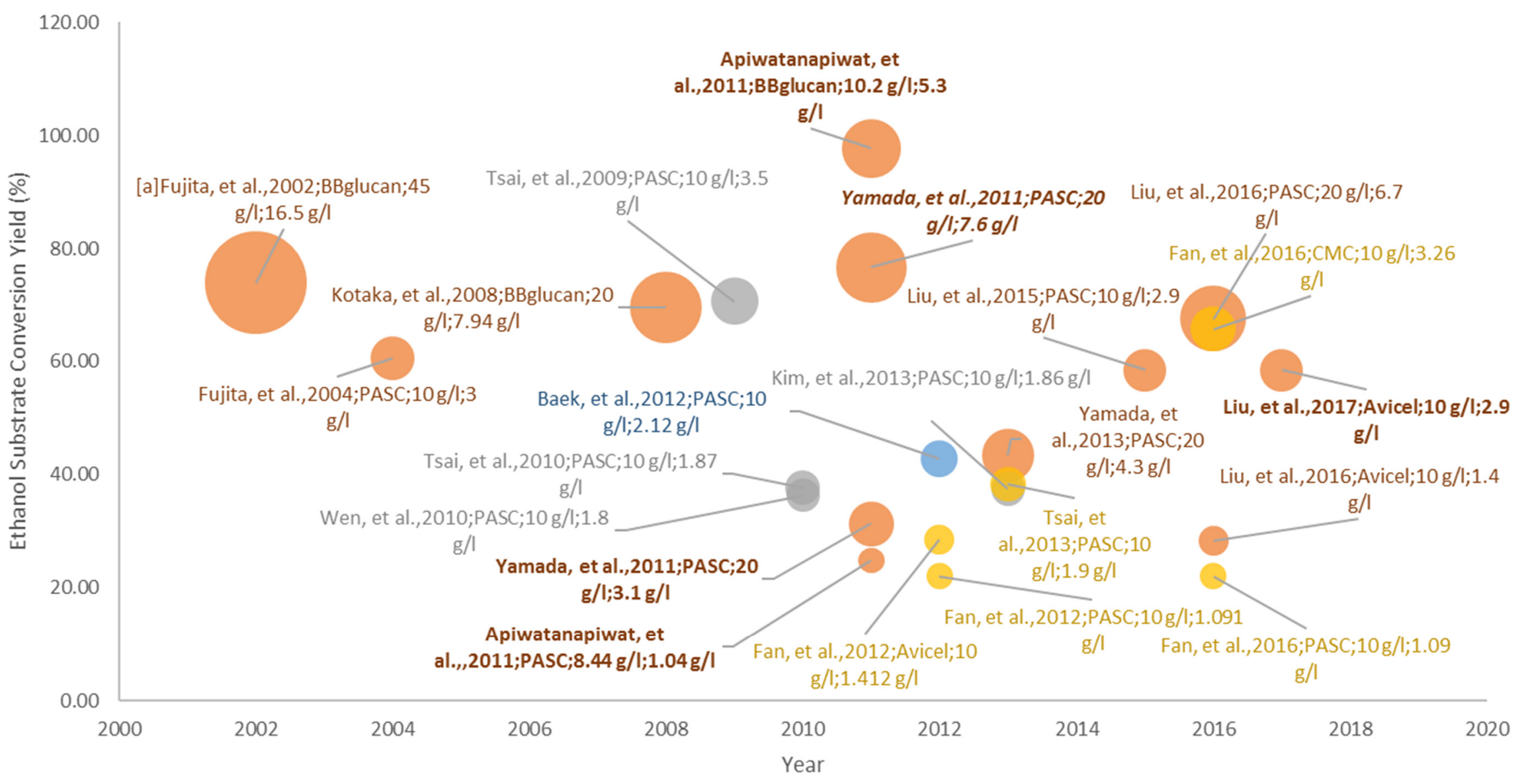

Figure 6. Visualization of the status and development of yeast surface display for Cellulosic Bioethanol Production. Bubble sizes represent ethanol titer. Data labels are formatted as follows: (Reference (author-date); Substrate; Substrate Concentration; Ethanol Titer). For the DSYD-CD data set: labels in boldface represent cellulase ratio control via delta-integration; labels in italic represent utilization of diploid host strains. 
- DSYD-SEDC • DSYD-CD - JANNASEY-SMFAA

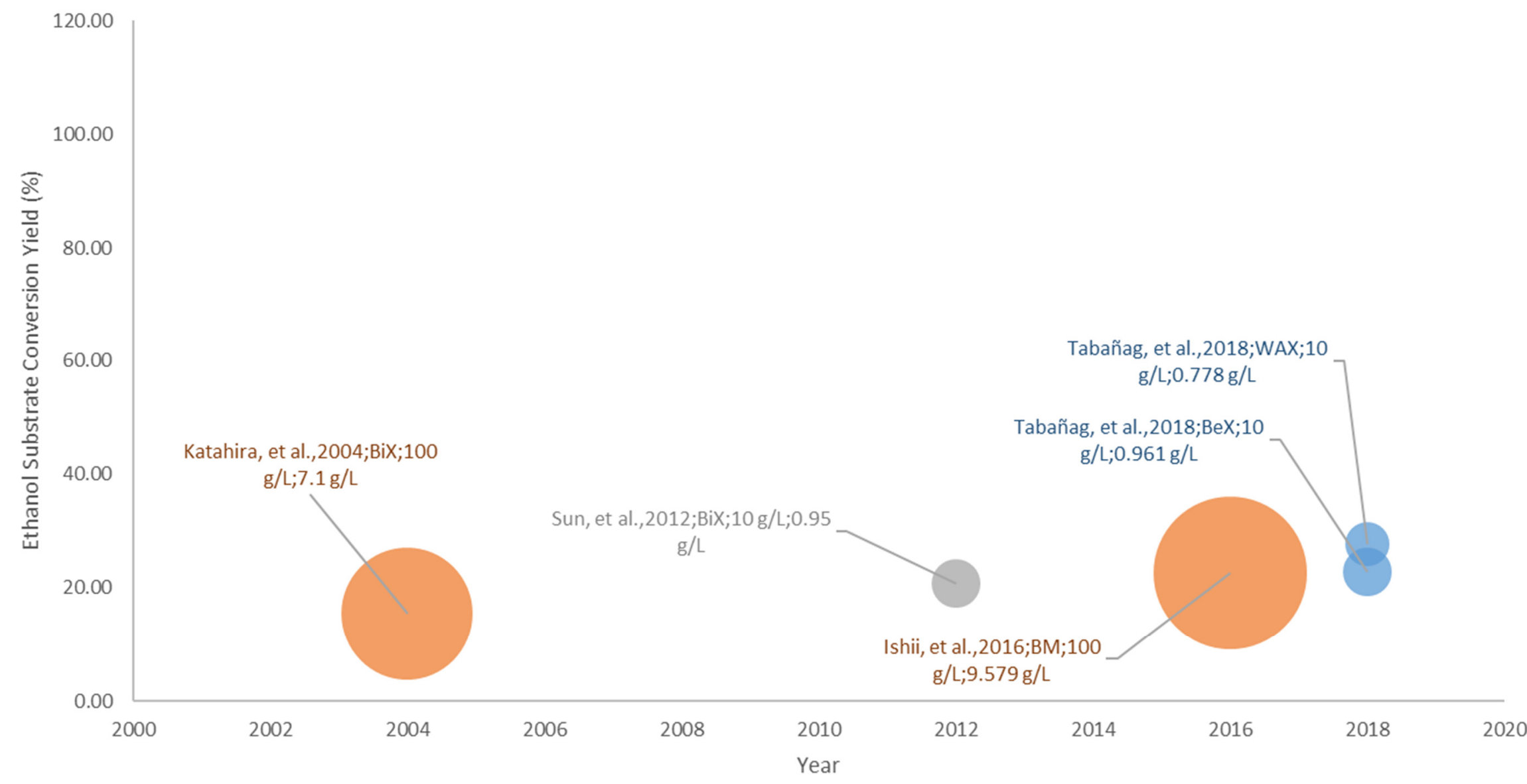

Figure 7. Visualization of the status and development of yeast surface display for Hemicellulosic Bioethanol Production. Bubble sizes represent ethanol titer. Data labels are formatted as follows: (Reference (author-date); Substrate; Substrate Concentration; Ethanol Titer). 
- DYSD-SEDC DYSD-CD

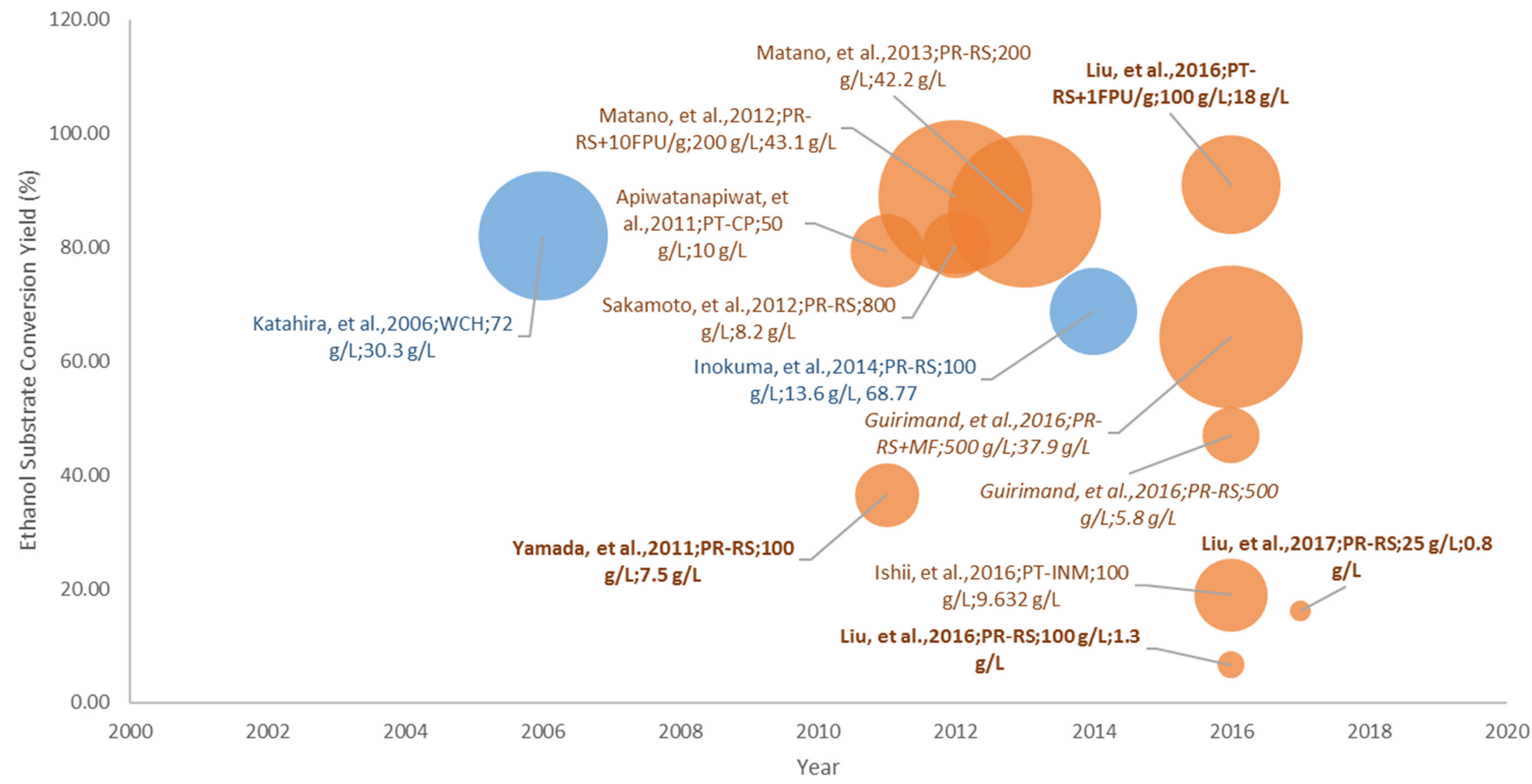

Figure 8. Visualization of the status and development of yeast surface display for Bioethanol Production from Pre-Treated Lignocellulosic Biomass. Bubble sizes represent ethanol titer. Data labels are formatted as follows: (Reference (author-date); Substrate; Substrate Concentration; Ethanol Titer). For DSYD-CD data sets: labels in boldface represent cellulase ratio control via delta-integration; labels in italic represent the xylitol fermentation parameters instead of ethanol. 


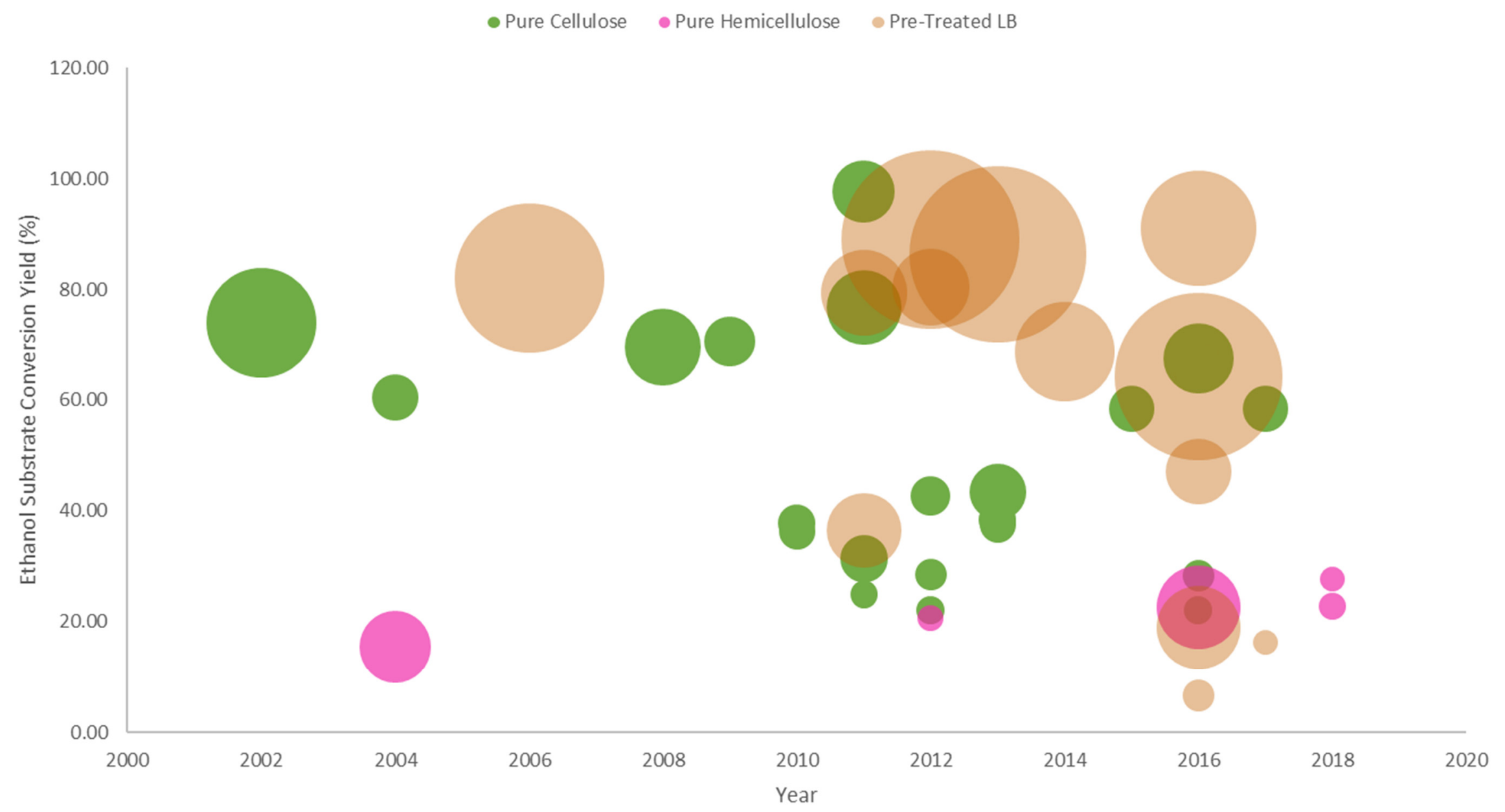

Figure 9. Visualization of the status and development of yeast surface display for Bioethanol Production categorized for the substrate types presented in this article. Bubble sizes represent ethanol titer. 


\section{Avenues of Improvement for Bioethanol Production Using Yeast Surface Display}

As discussed in Section 3.4, the comparative data analysis that are visualized and provided in the bubble charts do not imply the efficiency of a particular surface display strategy to a particular substrate. It just gives an idea on the performance of the engineered strains applying those strategies for the target substrate that it was assessed on. Figure 9 illustrates the impact of yeast surface display to the bioethanol production between the pure polysaccharide and the actual pre-treated lignocellulosic biomass substrates. Moreover, yeast surface display has played an important role in creating engineered strains that obtain high ethanol titers from pre-treated lignocellulosic substrates.

Using the visualized data sets as a guide, we can synthesize from those various techniques on improving the design of the engineered yeast tailored for the efficient degradation and utilization of a target substrate. These techniques are schematically illustrated in Figure 10.

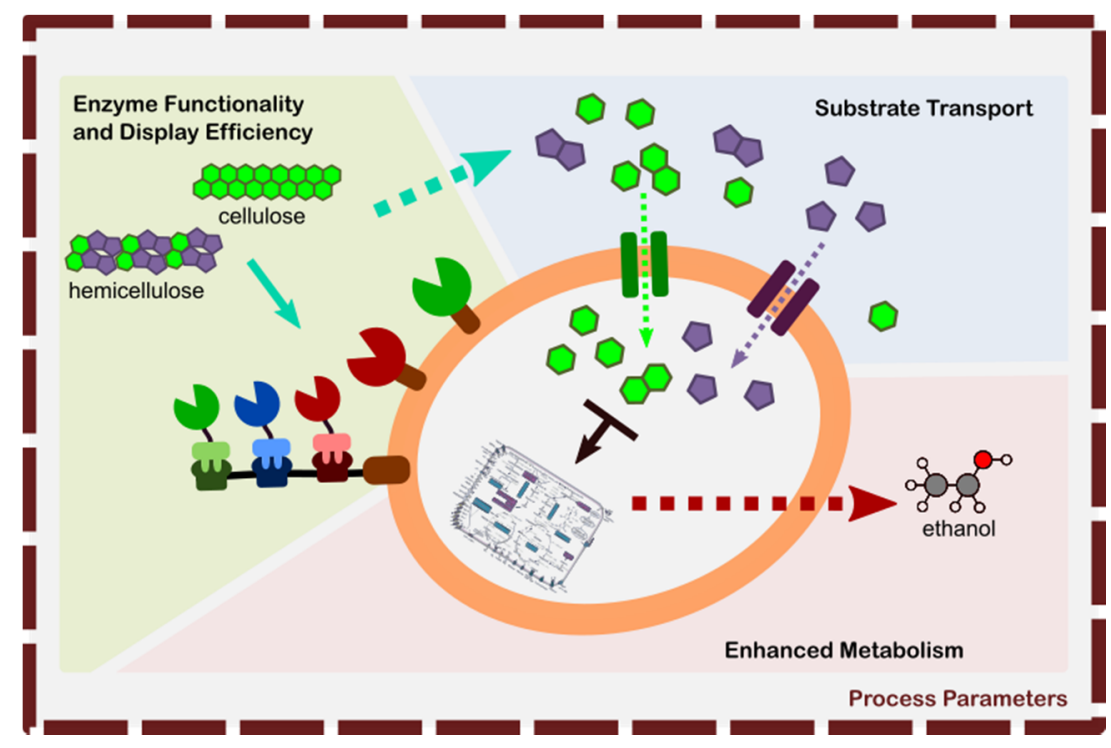

Figure 10. Schematic illustration for the different avenues of improvement for yeast surface display in bioethanol fermentation from lignocellulosic biomass.

These avenues of improvement are categorized into:

1. Enhancement of Enzyme Functionality, and Display Efficiency-this area involves the following: nature of the enzyme being expressed in yeast that it may either retain or increase its activity upon heterologous expression (functionality), enhanced surface display efficiency for DYSD strategy, and adaptor assembly for JANNASEY strategy. The main goal of this area is to increase the hydrolysis efficiency of the resulting strain to optimally liberate the fermentable sugars from their lignocellulosic structure.

2. Substrate Transport into the Yeast Cell-this area involves the efficient transport of the fermentable sugars into the cell. The goal is to provide efficient means transport for the different sugars (e.g., hexose, pentose, cellobiose) where the route is either specific to one type of sugar or a ubiquitous type for generic sugar transport.

3. Metabolic Engineering for Efficient Ethanol Conversion-involves in the rewiring of the yeast itself to convert the sugars efficiently into ethanol by minimizing the generation of by-products.

4. Optimization of Process Conditions for Enhanced Hydrolysis and Ethanol Production-optimization of the process conditions can either have an effect all the areas 1 to 3 or to one of them. This involves varying the process conditions (i.e., temperature, $\mathrm{pH}$, media composition, induction) to achieve efficient enzymatic hydrolysis and cellular metabolism. 


\subsection{On the Enzyme Functionality and Display Efficiency}

Enzyme functionality refers to the retention or improvement of the enzyme activity once heterologously expressed in yeast. This is mainly achieved by a combination of high throughput screening and protein engineering methodologies where the enzymes are tailored for functional expression in yeast that they synergistically interact with other enzymes expressed when it comes to the efficient hydrolysis of lignocellulosic substrates [81,100,108]. Likewise, the functional expression and display of novel enzymes derived from other microorganisms that has undergone some evolution (be it natural or engineered) contributes to the enhancement of hydrolysis activities once they act in concert with other novel enzymes [109-111].

On the other hand, enhancing the display efficiency of enzymes can be achieved by several approaches. In reference to the review of Tanaka, et al. [27], these approaches are classified as the traditional, semi-rational, and combinatorial approaches. The traditional approach targets the yeast secretion pathway itself and the detailed knowledge on yeast secretion has enabled increased secretion efficiency and protein yields. This was achieved through the utilization of various molecular techniques that lead to the optimization of signal sequences, upregulation of ER folding, modification of vesicle transport, and deletion of host proteinases as discussed in detail by Haan, et al. [112]. A recent example of this in relation to the role of surface display for efficient lignocellulose utilization has been demonstrated by Tang, et al. [113]. Where the localization and co-display of the $C$. thermocellum endoglucanase (CelA) along with a S. fibuligera $\beta$-glucosidase (BGL) was improved by the over-expression of various vesicle trafficking components. Furthermore, their results have shown that there is a protein-specific effect, which limit the vesicle trafficking pathway with respect to the heterologous protein being localized; this provides an insight on how to improve surface display efficiency tailored to the protein of interest [113]. In the semi-rational approach, the genes in the cell wall environment are targeted instead of those in the secretory pathway. These target proteins at the cell wall niche are either deleted or over-expressed. Kotaka, et al. [114] have demonstrated that by deleting the SED1 in the sake yeast displaying the A. oryzae $\beta$-glucosidase (BGL) anchored via the truncated $\alpha$-agglutinin anchor protein (SAG1, C-terminal half), the activity of BGL on the yeast surface was enhanced by $\sim 1.6$ fold when compared to the wild type; which can be attributed to the increased number of BGL displayed on the yeast surface [114]. In addition, Matsuoka, et al. [115], using a high throughput screening methodology, have identified the potential genes for deletion to enhance surface display efficiency. Screening results indicated that the deletion of the Mnn2 facilitated in the binding of high-molecular weight substrates to the active sites of the displayed enzymes thus improved the cellulase activities each displayed on the yeast surface by $\sim 1.6$, and $\sim 2$-fold for BGL and endoglucanase, respectively, with respect to their wild-type counterparts [115]. Lastly, the combinatorial approach which combines the high throughput screening methodology with a yeast overexpression library and yeast surface display. This novel screening approach described by Wentz and Shusta [116], has enabled rapid flow cytometric screening of engineered yeast for gene products that improve the display of heterologous proteins. Screening results have identified the ribosomal subunit protein (RPP0, for the overexpression of translational components), an endoplasmic reticulum resident protein (ER01, a folding assistant), and cell-wall related proteins (e.g., SED1, CCW12, CWP2) as general enhancers in target protein secretion; where secretion levels of the target protein was increased by $\sim 2$-fold to 8-fold with ER01 and CCW12 being the notable enhancers. Their results further suggest that display efficiency is dependent on the characteristics of both the target and anchor proteins [116].

\subsection{On Substrate Transport}

It can be said that substrate transport is what dictates how efficient the substrate can be converted into the desired product via metabolism. Since metabolism occurs in such a short period of time due to their low local concentration inside the cell, it results to a short passage time of molecules inside the cell; where the cell is in somewhat a pseudo-steady state. Thus, because of this transient residence time inside the cell, substrate conversion is dependent on the uptake rate and this is under the 
direct control of the substrate transporter [117]. The ideal substrate transporter should be ubiquitous and has no preference such that various substrates can be transported into the cell at almost equal uptake rates which lead to efficient and simultaneous conversion of multiple substrates into desired products. However in yeast, sugar transporters exhibit substrate preference or selectivity; meaning that it has high transport rates for its preferred sugars and low or blocked transport for its non-preferred sugars [118-120]. The quest to tailor or improve the substrate uptake of a specific transporter in yeast is explored in the field of "yeast transporter engineering". One of the major milestones of this field (during the investigation and characterization of the sugar transport mechanism in yeast) is the creation of a yeast strain (named EB.VW4000 [121]) that is devoid of 20 hexose transporter genes, which resulted in the inability of the strain to take up glucose and also fructose, galactose, and mannose. This strain has been an essential tool for the elucidation of transporter function; for engineering and screening either native or heterologous sugar transporters [122].

A good discussion on the role of yeast transformer engineering in the utilization of various sugars released from lignocellulosic biomass hydrolysis is reviewed by Hara, et al. [123]. The sugar transporters that have been engineered and expressed for consolidated bioprocessing (CBP) are those specific for the sugars derived from lignocellulosic biomass hydrolysates. These sugar transporters are designed and are currently developed specifically for the transport of: (i) cellobiose or cellodextrin from cellulose, (ii) xylose, arabinose, and galactose from hemicellulose, and (iii) sucrose and fructose from starchy plant materials. The details on the identity and the protein engineering methods for the transporters of the said sugars are as provided in the reference material [123].

In the studies presented in Section 3, so far only the combination of the cellobiose transport and utilization pathway with yeast surface display been explored for the direct co-display (DYSD) [68], and complex adaptor assembly strategies (JANNASEY) [77]. Thus, the integration of enhanced substrate uptake with yeast surface display is a challenging area that is not yet fully explored and could provide insights on the substrate channeling phenomenon from the displayed enzymes into the cell via the substrate transporter of interest.

\subsection{On Metabolic Engineering for Improved Ethanol Prodution}

The inherent ability of the yeast $S$. cerevisiae to produce ethanol has been its major industrial selling point for many years. It is considered as a natural ethanologen (ethanol-producing microbe) that can produce high amounts of ethanol titer from hexose sugars, especially glucose. This capability of yeast is what made it the ideal host microorganism for consolidated bioprocessing (CBP). When the CBP strategy was first introduced, the ideal target substrate for direct ethanol conversion was cellulose (since it mainly consists of linked glucose monomers); this was termed as microbial cellulose utilization [6,8-10]. Thus, it can be observed from Figure 9 that cellulose was the first substrate type that was explored by the yeast surface display strategies for CBP. In contrast to hemicellulose (which is pre-dominantly composed of xylan from plant-based/agricultural waste biomass) where its major fermentable sugar is xylose, where extra efforts to confer a xylose utilization pathway are needed prior to ethanol production.

In terms of the combined xylose utilization from hemicellulosic substrates and yeast surface display strategies, combining the XR-XDH xylose utilization pathway with direct co-display (DSYD-CD) and with single multi-functional adaptor assembly (JANNASEY-SMFAA) has been reported by Katahira, et al. [95] and Sun, et al. [99], respectively, while combining the XI-XK xylose utilization pathway with the single enzyme display consortium (DYSD-SEDC) has been reported by Tabañag and Tsai [42]. Though the reported ESCY's of these studies mentioned are quite low $(<30 \%)$, these could be improved by the combination of metabolic and evolutionary engineering methodologies. As the xylose conversion to ethanol occurs via the pentose-phosphate pathway (PPP), the metabolic engineering of the downstream PPP genes has been reported to have high specific rates of anaerobic xylose consumption and ethanol production [124,125]. Moreover, combining this metabolic engineering strategy to overexpress xylose-utilization pathway and downstream PPP genes 
with systematic evolutionary engineering techniques can further improve xylose utilization, ethanol production, and even inhibitor tolerance [126-130].

\subsection{On Process Parameters}

In a fermentation system, the conditions of the area surrounding the cell constitute the process parameters. This involves the physiological conditions surrounding the cell (e.g., temperature, $\mathrm{pH}$, media, inhibitors), the type of yeast utilized in the process, and mode of cultivation. Furthermore, when target enzymes are displayed on the yeast surface, it exhibits enhancements on their relative activities and stability; and to some degree that these enhancements especially on a physiological level where there is increased tolerance to some medium components. This two-way enhancement is one of the attractive features that elevate the status of yeast from an immobilization platform to a whole-cell biocatalyst.

\subsubsection{Cultivation Conditions}

The feature of yeast surface display systems once they are in the fermentation environment is that continuous enzyme regeneration (induction) and display on the surface of yeast is coupled with cell growth. Thus, a properly formulated medium can provide an avenue for optimized enzyme expression. From the presented studies in Section 3, Fan, et al. [77] supplemented their fermentation media with galactose for the continuous expression of their adaptor protein vital for the cellulosome assembly. Since other surface display systems are designed with the constitutive (always on) enzyme expression condition kept in mind, then it is the fermentation medium composition (given that one component is a limiting substrate) that directs enzyme expression and display, along with the substrate utilization and conversion.

In terms of hydrolytic activity, most of the enzymes that are heterologously expressed in yeast exhibit optimum activities at high temperatures (typically $50-60{ }^{\circ} \mathrm{C}$ ), while the optimal growth conditions for $S$. cerevisiae is at a significantly lower temperature $\left(25-35{ }^{\circ} \mathrm{C}\right)$. Thus, there should be a compromise between the hydrolysis activity and yeast growth, and in most cases yeast growth is always favored at $30{ }^{\circ} \mathrm{C}$, which results in a 2-3-fold decrease in the hydrolytic activity of the said enzymes. Thus, for yeast display systems, the temperature can be optimized to achieve the optimum hydrolytic activity and ethanol conversion. Khatun, et al. [131] have demonstrated that at an elevated temperature of $40^{\circ} \mathrm{C}$, ethanol production of an inulinase displaying industrial yeast strain has enhanced when fermented on inulin and Jerusalem artichoke tubers (a starchy substrate) [131].

\subsubsection{Host Strain Type}

The use of industrial ethanol yeast strains as a host for the yeast surface display technology can enhance ethanol production from pre-treated substrates as these strains are naturally being exposed in a constant selective pressure (continuous utilization in an industrial setting), which can give rise to high ethanol producing mutants. The utilization of an industrial sake yeast displaying cellulases has produced a high amount of ethanol from a pure cellulosic substrate, as demonstrated by Kotaka, et al. [60]. Furthermore, the same effect can be observed in some extent when the engineered yeast strains displaying cellulases undergo diploidization by mating and assessed on their ethanol fermentation performance, around a 2.5-fold increase in ESCY was observed when comparing the diploid strain with the haploid one, as reported by Yamada, et al. [66]. This strategy is based on the fact that polyploid (including diploid) strains have higher cell growth rates, cell yields, and tolerances to various stresses when compared with haploid strains; wild type industrial yeast strains are diploid (which has both the a, and $\alpha$ mating types).

\subsubsection{Inhibitor Removal by Additional Process Treatment Steps}

The presence of inhibitors decrease the expected ethanol yield in during the fermentation. The presence of these inhibitors adversely affect the cell growth and metabolism. Thus, their removal 
presents another round of pre-treatment step/s. Guirimand, et al. [106] have removed these inhibitors from rice straw hydrolysate by membrane filtration and at the same time concentrated the fermentable sugars. Obtained xylitol yield (XSCY) from the membrane-filtered hydrolysate is 1.4-times higher than the non-filtered, with an approximately 10-fold difference in xylitol titer obtained with respect to the non-filtered hydrolysate.

Another treatment step is by enzymatic degradation of these inhibitors. Nakanishi, et al. [132] have utilized yeast displaying the white rot fungus Trametes sp. Ha1 laccase I (LacI) on its surface in the pre-treatment of hydrothermally processed rice straw. Another strain that co-displays three cellulases was used to assess the efficiency of pre-treatment and it was found out that the ethanol productivity from the laccase pre-treatment of rice straw was 1.2 -times higher than the one with no treatment

\section{Conclusions}

The construction of recombinant yeast strains that display different enzymes via different surface display strategies have played a significant role in the quest of finding the ideal CBP strain. In most of the studies that are presented in this article, the performance of the displayed enzymes on yeast was deemed superior in contrast to their free enzyme counterparts. Furthermore, the different strategies for yeast surface display and their features were discussed and their performance on bioethanol production from lignocellulosic biomass substrates were assessed. The trends and progress in lignocellulosic bioethanol production using the surface-engineered yeasts were evaluated using comparative data analysis and visualization techniques. The resulting data visualization charts serve as a reference material on the status on how the different surface display strategies have affected the ethanol substrate conversion yields between pure polysaccharide and pre-treated lignocellulosic biomass substrates. On the other hand, a discussion on the strategic areas of development for tailoring yeast with surface display technology for lignocellulosic bioethanol production was synthesized to serve as a reference on as to how this field of study will advance.

Acknowledgments: We are grateful to Peter Grunwald (the Guest Editor of Catalysts) and Adela Liao (the Managing Editor of MDPI) for inviting us to submit this review. We would like to acknowledge the jointed financial support from Chang Chun Group and the Ministry of Science and Technology, Taiwan. (MOST 105-2622-8-007-009).

Author Contributions: Ian Dominic Flormata Tabañag and Shen-Long Tsai defined the scope and structure of the paper. Ian Dominic Flormata Tabañag, I-Ming Chu, Yu-Hong Wei and Shen-Long Tsai all participated in the discussion, writing and revision of the paper.

Conflicts of Interest: The authors declare no conflict of interest. 


\section{Appendix}

Table A1. List of references collated with respect to the substrate types targeted by the different yeast surface display technologies.

\begin{tabular}{|c|c|c|c|c|c|c|c|c|c|}
\hline Authors & Year & Refs. & $\begin{array}{c}\text { Yeast Surface Display } \\
\text { Strategy }\end{array}$ & $\begin{array}{l}\text { Anchoring } \\
\text { Protein }\end{array}$ & Subst. Abbrv & $\begin{array}{c}\text { Substrate } \\
\text { Conc. }(\mathrm{g} / \mathrm{L})\end{array}$ & Ethanol Titer $(\mathrm{g} / \mathrm{L})$ & Ferm. Time. (h) & $\operatorname{ESCY}(\%)^{i}$ \\
\hline \multicolumn{10}{|c|}{ PURE CELLULOSE SUBSTRATES } \\
\hline a Fujita, et al. & 2002 & [58] & DYSD-CD & SAG1 (3'-half) & BBglucan & 45 & 16.5 & 48 & 73.97 \\
\hline Fujita, et al. & 2004 & [59] & DYSD-CD & SAG1 (3'-half) & PASC & 10 & 3 & 40 & 60.52 \\
\hline Kotaka, et al. & 2008 & [60] & DYSD-CD & SAG1 (3'-half) & BBglucan & 20 & 7.94 & 24 & 69.60 \\
\hline Tsai, et al. & 2009 & [46] & JANNASEY-SMFAA & AGA1::AGA2 & PASC & 10 & 3.5 & 50 & 70.61 \\
\hline Tsai, et al. & 2010 & [72] & JANNASEY-SMFAA & AGA1::AGA2 & PASC & 10 & 1.87 & 70 & 37.73 \\
\hline Wen, et al. & 2010 & [73] & JANNASEY-SMFAA & AGA1::AGA2 & PASC & 10 & 1.8 & 70 & 36.31 \\
\hline Apiwatanapiwat, et al. & 2011 & \multirow{2}{*}{ [67] } & DYSD-CD & SAG1 (3'-half) & BBglucan & 10.2 & 5.3 & 36 & 97.70 \\
\hline Apiwatanapiwat, et al. & 2011 & & DYSD-CD & SAG1 (3'-half) & PASC & 8.44 & 1.04 & n.r. & 24.86 \\
\hline Yamada, et al. & 2011 & \multirow{2}{*}{ [66] } & DYSD-CD & SAG1 (3'-half) & PASC & 20 & 3.1 & 72 & 31.27 \\
\hline Yamada, et al. & 2011 & & DYSD-CD & SAG1 (3'-half) & PASC & 20 & 7.6 & 72 & 76.66 \\
\hline Baek, et al. & 2012 & [45] & DYSD-SEDC & SAG1 (3'-half) & PASC & 10 & 2.12 & 85 & 42.77 \\
\hline Fan, et al. & 2012 & \multirow{2}{*}{ [75] } & JANNASEY-CAA & AGA1::AGA2 & PASC & 10 & 1.091 & 96 & 22.01 \\
\hline Fan, et al. & 2012 & & JANNASEY-CAA & AGA1::AGA2 & Avicel & 10 & 1.412 & 96 & 28.49 \\
\hline Tsai, et al. & 2013 & [76] & JANNASEY-CAA & AGA1::AGA2 & PASC & 10 & 1.9 & 72 & 38.33 \\
\hline Yamada, et al. & 2013 & [68] & DYSD-CD & SAG1 (3'-half) & PASC & 20 & 4.3 & 72 & 43.38 \\
\hline Kim, et al. & 2013 & [74] & JANNASEY-SMFAA & AGA1::AGA2 & PASC & 10 & 1.86 & 94 & 37.52 \\
\hline Liu, et al. & 2015 & [61] & DYSD-CD & SED1 & PASC & 10 & 2.9 & 96 & 58.51 \\
\hline Fan, et al. & 2016 & \multirow{2}{*}{ [77] } & JANNASEY-CAA & AGA1::AGA2 & $\mathrm{CMC}$ & 10 & 3.26 & 60 & 65.77 \\
\hline Fan, et al. & 2016 & & JANNASEY-CAA & AGA1::AGA2 & PASC & 10 & 1.09 & 60 & 21.99 \\
\hline Liu, et al. & 2016 & \multirow{2}{*}{ [62] } & DYSD-CD & SED1 & PASC & 20 & 6.7 & 96 & 67.59 \\
\hline Liu, et al. & 2016 & & DYSD-CD & SED1 & Avicel & 10 & 1.4 & 96 & 28.24 \\
\hline Liu, et al. & 2017 & [69] & DYSD-CD & SED1 & Avicel & 10 & 2.9 & 96 & 58.51 \\
\hline \multicolumn{10}{|c|}{$\begin{array}{l}\text { PURE HEMICELLULOSE SUBSTRATES } \\
\end{array}$} \\
\hline Fujita, et al. & 2002 & [96] & DYSD-CD & SAG1 (3'-half) & BiX & 10 & n.r. & n.r. & n.r. \\
\hline Katahira, et al. & 2004 & [95] & DYSD-CD & SAG1 (3'-half) & BiX & 100 & 7.1 & 62 & 15.44 \\
\hline Sun et al. & 2012 & [99] & JANNASEY-SMFAA & AGA1::AGA2 & BiX & 10 & 0.95 & 80 & 20.66 \\
\hline Ishii, et al. & 2016 & [43] & DYSD-CD & Flo $428 p$ & BM & 100 & 9.579 & 312 & 22.59 \\
\hline Tabañag, et al. & 2018 & \multirow{2}{*}{ [42] } & DYSD-SEDC & SAG1 (3'-half) & BeX & 10 & 0.961 & 168 & 22.77 \\
\hline Tabañag, et al. & 2018 & & DYSD-SEDC & SAG1 (3'-half) & WAX & 10 & 0.778 & 168 & 27.66 \\
\hline
\end{tabular}


Table A1. Cont.

\begin{tabular}{|c|c|c|c|c|c|c|c|c|c|}
\hline Authors & Year & Refs. & $\begin{array}{l}\text { Yeast Surface Display } \\
\text { Strategy }\end{array}$ & $\begin{array}{c}\text { Anchoring } \\
\text { Protein }\end{array}$ & Subst. Abbrv & $\begin{array}{c}\text { Substrate } \\
\text { Conc. (g/L) }\end{array}$ & Ethanol Titer $(\mathrm{g} / \mathrm{L})$ & Ferm. Time. (h) & $\operatorname{ESCY}(\%)^{i}$ \\
\hline \multicolumn{10}{|c|}{$\begin{array}{l}\text { PRE-TREATED LIGNOCELLULOSIC BIOMASS SUBSTRATES } \\
\end{array}$} \\
\hline Murai, et al. & 1998 & [133] & DYSD-SEDC & SAG1 (3'-half) & $\mathrm{RCS}^{\mathrm{ii}}$ & 625 & 23.25 & 168 & n.r. \\
\hline Murai, et al. & 1998 & [134] & DYSD-SEDC & SAG1 (3'-half) & RCS+Term. ii & 626 & 53 & 169 & n.r. \\
\hline Katahira, et al. & 2006 & [107] & DYSD-CD & SAG1 (3'-half) & WCH & 72 & 30.3 & 36 & 80.39 \\
\hline Kotaka, et al. & 2008 & [135] & DYSD-CD & SAG1 (3'-half) & LCS & 50 & 20 & 48 & n.r. \\
\hline Apiwatanapiwat, et al. & 2011 & [67] & DYSD-CD & SAG1 (3'-half) & PT-CP & 50 & 10 & 48 & 79.40 \\
\hline Sakamoto, et al. & 2012 & [105] & DYSD-CD & SAG1 (3'-half) & PT-RS & 800 & 8.2 & 72 & 80.39 \\
\hline Matano, et al. & 2012 & [103] & DYSD-CD & SAG1 (3'-half) & PT-RS & 200 & 43.1 & 72 & 89.00 \\
\hline Matano, et al. & 2013 & [104] & DYSD-CD & SAG1 (3'-half) & PT-RS & 200 & 42.2 & 360 & 86.30 \\
\hline Yamada, et al. & 2011 & [66] & DYSD-CD & SAG1 (3'-half) & PT-RS & 100 & 7.5 & 72 & 33.00 \\
\hline Inokuma, et al. & 2014 & [136] & DYSD-SEDC & SED1 & PT-RS-SF+CTec2 & 100 & 13.6 & 96 & 68.77 \\
\hline Guirimand, et al. & 2016 & \multirow{2}{*}{ [106] } & DYSD-CD & SED1 & PT-RSH & 500 & 5.8 & 96 & 79.48 \\
\hline Guirimand, et al. & 2016 & & DYSD-CD & SED1 & PT-RSH & 500 & 37.9 & 96 & 63.38 \\
\hline Ishii, et al. & 2016 & [43] & DYSD-CD & Flo428p & PT-INM & 100 & 9.632 & 216 & 18.89 \\
\hline Liu, et al. & 2016 & \multirow{2}{*}{ [62] } & DYSD-CD & SED1 & PT-RS-SF & 100 & 1.3 & 96 & 7.00 \\
\hline Liu, et al. & 2016 & & DYSD-CD & SED1 & PT-RS-SF+CTec2 & 100 & 18 & 96 & 80.00 \\
\hline Liu, et al. & 2017 & [69] & DYSD-CD & SED1 & PT-RS & 25 & 0.8 & 96 & n.r. \\
\hline \multicolumn{10}{|c|}{ Other Studies } \\
\hline Murai, et al. & 1997 & [137] & DYSD-CD & SAG1 (3'-half) & n.r. & n.r. & n.r. & n.r. & n.r. \\
\hline Fukuda, et al. & 2007 & [111] & DYSD-SEDC & SAG1 (3'-half) & n.r. & n.r. & n.r. & n.r. & n.r. \\
\hline Lilly, et al. & 2009 & [71] & JANNASEY-SMFAA & Cwp2 & n.r. & n.r. & n.r. & n.r. & n.r. \\
\hline Kotaka, et al. & 2010 & [114] & DYSD-SEDC & SAG1 (3'-half) & n.r. & n.r. & n.r. & n.r. & n.r. \\
\hline Yeasmin, et al. & 2011 & [110] & DYSD-SEDC & AGA1::AGA2 & n.r. & n.r. & n.r. & n.r. & n.r. \\
\hline Gao, et al. & 2017 & [109] & DYSD-SEDC & AGA1::AGA2 & n.r. & n.r. & n.r. & n.r. & n.r. \\
\hline Tang, et al. & 2017 & [113] & DYSD-CD & AGA1::AGA2 & n.r. & n.r. & n.r. & n.r. & n.r. \\
\hline
\end{tabular}

i mostly recalculated from the data of the presented studies using Equation (1); ii though classified in Pre-Treated lignocellulosic biomass, these feedstock are considered as "first generation" which means that these compete with the food supply thus were not considered during the presentation and visualization of data., ${ }^{a}$ distinction from ref. [96]; n.r.- not reported 


\section{References}

1. Stocker, T.F.; Qin, D.; Plattner, G.-K.; Tignor, M.M.B.; Allen, S.K.; Boschung, J.; Nauels, A.; Xia, Y.; Bex, V.; Midgley, P.M. Climate Change 2013: The Physical Science Basis: Working Group 1 Contribution to the Fifth Assessment Report of the Intergovernmental Panel on Climate Change; Cambridge University Press: Cambridge, UK, 2014.

2. Ronzon, T.; Lusser, M.; Klinkenberg, M.; Landa, L.; Lopez, J.S.; M’Barek, R.; Hadjamu, G.; Belward, A.; Camia, A.; Giuntoli, J.; et al. Bioeconomy Report 2016; European Commission: Brussels, Belgium, 2017.

3. Langeveld, H.; Sanders, J.; Meeusen, M. The Biobased Economy: Biofuels, Materials and Chemicals in the Post-Oil Era; Earthscan LLC: London, UK, 2012.

4. Commission, E. Innovating for Sustainable Growth: A Bioeconomy for Europe; European Commission: Brussels, Belgium, 2012.

5. De Jong, E. Bio-Based Chemicals Value Added Products from Biorefineries; IEA Bioenergy-Task 42 Biorefinery: Wageningen, The Netherlands, 2012.

6. Lynd, L.R.; Weimer, P.J.; van Zyl, W.H.; Pretorius, I.S. Microbial cellulose utilization: Fundamentals and biotechnology. Microbiol. Mol. Biol. Rev. 2002, 66, 506-577. [CrossRef] [PubMed]

7. Kricka, W.; Fitzpatrick, J.; Bond, U. Metabolic engineering of yeasts by heterologous enzyme production for degradation of cellulose and hemicellulose from biomass: A perspective. Front. Microbiol. 2014, 5, 174. [CrossRef] [PubMed]

8. Lynd, L.R.; van Zyl, W.H.; McBride, J.E.; Laser, M. Consolidated bioprocessing of cellulosic biomass: An update. Curr. Opin. Biotechnol. 2005, 16, 577-583. [CrossRef] [PubMed]

9. Olson, D.G.; McBride, J.E.; Shaw, A.J.; Lynd, L.R. Recent progress in consolidated bioprocessing. Curr. Opin. Biotechnol. 2012, 23, 396-405. [CrossRef] [PubMed]

10. Van Zyl, W.; Lynd, L.; den Haan, R.; McBride, J. Consolidated bioprocessing for bioethanol production using Saccharomyces cerevisiae. In Biofuels; Olsson, L., Ed.; Springer: Berlin/Heidelberg, Germany, 2007; Volume 108, pp. 205-235.

11. Chiswell, D.J.; McCaffery, J. Phage antibodies: Will new 'coliclonal' antibodies replace monoclonal antibodies? Trends Biotechnol. 1992, 10, 80-84. [CrossRef]

12. Scott, J.K.; Smith, G.P. Searching for peptide ligands with an epitope library. Science 1990, 249, $386-390$. [CrossRef] [PubMed]

13. Georgiou, G.; Stathopoulos, C.; Daugherty, P.S.; Nayak, A.R.; Iverson, B.L.; Iii, R.C. Display of heterologous proteins on the surface of microorganisms: From the screening of combinatorial libraries to live recombinant vaccines. Nat. Biotechnol. 1997, 15, 29. [CrossRef] [PubMed]

14. Little, M.; Fuchs, P.; Breitling, F.; Dübel, S. Bacterial surface presentation of proteins and peptides: An alternative to phage technology? Trends Biotechnol. 1993, 11, 3-5. [CrossRef]

15. Georgiou, G.; Poetschke, H.L.; Stathopoulos, C.; Francisco, J.A. Practical applications of engineering gram-negative bacterial cell surfaces. Trends Biotechnol. 1993, 11, 6-10. [CrossRef]

16. Michon, C.; Langella, P.; Eijsink, V.G.H.; Mathiesen, G.; Chatel, J.M. Display of recombinant proteins at the surface of lactic acid bacteria: Strategies and applications. Microb. Cell Fact. 2016, 15, 70. [CrossRef] [PubMed]

17. Schüürmann, J.; Quehl, P.; Festel, G.; Jose, J. Bacterial whole-cell biocatalysts by surface display of enzymes: Toward industrial application. Appl. Microbiol. Biotechnol. 2014, 98, 8031-8046. [CrossRef] [PubMed]

18. Desvaux, M.; Dumas, E.; Chafsey, I.; Hébraud, M. Protein cell surface display in gram-positive bacteria: From single protein to macromolecular protein structure. FEMS Microbiol. Lett. 2006, 256, 1-15. [CrossRef] [PubMed]

19. Lee, S.Y.; Choi, J.H.; Xu, Z. Microbial cell-surface display. Trends Biotechnol. 2003, 21, 45-52. [CrossRef]

20. Ståhl, S.; Uhlén, M. Bacterial surface display: Trends and progress. Trends Biotechnol. 1997, 15, $185-192$. [CrossRef]

21. Van Bloois, E.; Winter, R.T.; Kolmar, H.; Fraaije, M.W. Decorating microbes: Surface display of proteins on escherichia coli. Trends Biotechnol. 2011, 29, 79-86. [CrossRef] [PubMed]

22. Wittrup, K.D. Protein engineering by cell-surface display. Curr. Opin. Biotechnol. 2001, 12, 395-399. [CrossRef]

23. Murai, T.; Ueda, M.; Shibasaki, Y.; Kamasawa, N.; Osumi, M.; Imanaka, T.; Tanaka, A. Development of an arming yeast strain for efficient utilization of starch by co-display of sequential amylolytic enzymes on the cell surface. Appl. Microbiol. Biotechnol. 1999, 51, 65-70. [CrossRef] [PubMed] 
24. Ueda, M.; Tanaka, A. Cell surface engineering of yeast: Construction of arming yeast with biocatalyst. J. Biosci. Bioeng. 2000, 90, 125-136. [CrossRef]

25. Ueda, M.; Tanaka, A. Genetic immobilization of proteins on the yeast cell surface. Biotechnol. Adv. 2000, 18, 121-140. [CrossRef]

26. Kondo, A.; Ueda, M. Yeast cell-surface display-Applications of molecular display. Appl. Microbiol. Biotechnol. 2004, 64, 28-40. [CrossRef] [PubMed]

27. Tanaka, T.; Yamada, R.; Ogino, C.; Kondo, A. Recent developments in yeast cell surface display toward extended applications in biotechnology. Appl. Microbiol. Biotechnol. 2012, 95, 577-591. [CrossRef] [PubMed]

28. Hasunuma, T.; Kondo, A. Development of yeast cell factories for consolidated bioprocessing of lignocellulose to bioethanol through cell surface engineering. Biotechnol. Adv. 2012, 30, 1207-1218. [CrossRef] [PubMed]

29. Kuroda, K.; Ueda, M. Arming technology in yeast-Novel strategy for whole-cell biocatalyst and protein engineering. Biomolecules 2013, 3, 632-650. [CrossRef] [PubMed]

30. Tanaka, T.; Kondo, A. Cell-surface display of enzymes by the yeast Saccharomyces cerevisiae for synthetic biology. FEMS Yeast Res. 2015, 15, 1-9. [PubMed]

31. Ueda, M. Establishment of cell surface engineering and its development. Biosci. Biotechnol. Biochem. 2016, 80, 1243-1253. [CrossRef] [PubMed]

32. Cherry, J.M.; Hong, E.L.; Amundsen, C.; Balakrishnan, R.; Binkley, G.; Chan, E.T.; Christie, K.R.; Costanzo, M.C.; Dwight, S.S.; Engel, S.R.; et al. Saccharomyces genome database: The genomics resource of budding yeast. Nucleic Acids Res. 2012, 40, D700-D705. [CrossRef] [PubMed]

33. Wang, Z.; Mathias, A.; Stavrou, S.; Neville, J.D.M. A new yeast display vector permitting free SCFV amino termini can augment ligand binding affinities. Protein Eng. Des. Sel. 2005, 18, 337-343. [CrossRef] [PubMed]

34. Sato, N.; Matsumoto, T.; Ueda, M.; Tanaka, A.; Fukuda, H.; Kondo, A. Long anchor using Flo1 protein enhances reactivity of cell surface-displayed glucoamylase to polymer substrates. Appl. Microbiol. Biotechnol. 2002, 60, 469-474. [PubMed]

35. Matsumoto, T.; Fukuda, H.; Ueda, M.; Tanaka, A.; Kondo, A. Construction of yeast strains with high cell surface lipase activity by using novel display systems based on the Flo1p flocculation functional domain. Appl. Environ. Microbiol. 2002, 68, 4517-4522. [CrossRef] [PubMed]

36. Lamed, R.; Setter, E.; Bayer, E.A. Characterization of a cellulose-binding, cellulase-containing complex in clostridium thermocellum. J. Bacteriol. 1983, 156, 828-836. [PubMed]

37. Doi, R.H.; Kosugi, A. Cellulosomes: Plant-cell-wall-degrading enzyme complexes. Nat. Rev. Microbiol. 2004, 2, 541-551. [CrossRef] [PubMed]

38. Artzi, L.; Bayer, E.A.; Morais, S. Cellulosomes: Bacterial nanomachines for dismantling plant polysaccharides. Nat. Rev. Microbiol. 2017, 15, 83-95. [CrossRef] [PubMed]

39. Mitsuzawa, S.; Kagawa, H.; Li, Y.; Chan, S.L.; Paavola, C.D.; Trent, J.D. The rosettazyme: A synthetic cellulosome. J. Biotechnol. 2009, 143, 139-144. [CrossRef] [PubMed]

40. Nidetzky, B.; Steiner, W.; Hayn, M.; Claeyssens, M. Cellulose hydrolysis by the cellulases from trichoderma reesei: A new model for synergistic interaction. Biochem. J. 1994, 298, 705-710. [CrossRef] [PubMed]

41. Kumar, R.; Wyman, C.E. Effects of cellulase and xylanase enzymes on the deconstruction of solids from pretreatment of poplar by leading technologies. Biotechnol. Prog. 2009, 25, 302-314. [CrossRef] [PubMed]

42. Tabañag, I.D.; Tsai, S.-L. Hemicellulose degradation and utilization by a synthetic Saccharomyces cerevisiae consortium. bioRxiv 2018. [CrossRef]

43. Ishii, J.; Okazaki, F.; Djohan, A.C.; Hara, K.Y.; Asai-Nakashima, N.; Teramura, H.; Andriani, A.; Tominaga, M.; Wakai, S.; Kahar, P.; et al. From mannan to bioethanol: Cell surface co-display of $\beta$-mannanase and $\beta$-mannosidase on yeast Saccharomyces cerevisiae. Biotechnol. Biofuels 2016, 9, 188. [CrossRef] [PubMed]

44. Srikrishnan, S.; Chen, W.; Da Silva, N.A. Functional assembly and characterization of a modular xylanosome for hemicellulose hydrolysis in yeast. Biotechnol. Bioeng. 2013, 110, 275-285. [CrossRef] [PubMed]

45. Baek, S.-H.; Kim, S.; Lee, K.; Lee, J.-K.; Hahn, J.-S. Cellulosic ethanol production by combination of cellulase-displaying yeast cells. Enzyme Microb. Technol. 2012, 51, 366-372. [CrossRef] [PubMed]

46. Tsai, S.-L.; Oh, J.; Singh, S.; Chen, R.; Chen, W. Functional assembly of minicellulosomes on the Saccharomyces cerevisiae cell surface for cellulose hydrolysis and ethanol production. Appl. Environ. Microbiol. 2009, 75, 6087-6093. [CrossRef] [PubMed] 
47. Kondo, A.; Shigechi, H.; Abe, M.; Uyama, K.; Matsumoto, T.; Takahashi, S.; Ueda, M.; Tanaka, A.; Kishimoto, M.; Fukuda, H. High-level ethanol production from starch by a flocculent Saccharomyces cerevisiae strain displaying cell-surface glucoamylase. Appl. Microbiol. Biotechnol. 2002, 58, 291-296. [CrossRef] [PubMed]

48. Lin, L.; Yan, R.; Liu, Y.; Jiang, W. In-depth investigation of enzymatic hydrolysis of biomass wastes based on three major components: Cellulose, hemicellulose and lignin. Bioresour. Technol. 2010, 101, 8217-8223. [CrossRef] [PubMed]

49. Carere, C.R.; Sparling, R.; Cicek, N.; Levin, D.B. Third generation biofuels via direct cellulose fermentation. Int. J. Mol. Sci. 2008, 9, 1342-1360. [CrossRef] [PubMed]

50. Pérez, J.; Muñoz-Dorado, J.; de la Rubia, T.; Martínez, J. Biodegradation and biological treatments of cellulose, hemicellulose and lignin: An overview. Int. Microbiol. 2002, 5, 53-63. [CrossRef] [PubMed]

51. Zhang, X.-Z.; Sathitsuksanoh, N.; Zhang, Y.H.P. Glycoside hydrolase family 9 processive endoglucanase from clostridium phytofermentans: Heterologous expression, characterization, and synergy with family 48 cellobiohydrolase. Bioresour. Technol. 2010, 101, 5534-5538. [CrossRef] [PubMed]

52. Qi, M.; Jun, H.-S.; Forsberg, C.W. Characterization and synergistic interactions of fibrobacter succinogenes glycoside hydrolases. Appl. Environ. Microbiol. 2007, 73, 6098-6105. [CrossRef] [PubMed]

53. Zhang, Y.-H.P.; Lynd, L.R. Toward an aggregated understanding of enzymatic hydrolysis of cellulose: Noncomplexed cellulase systems. Biotechnol. Bioeng. 2004, 88, 797-824. [CrossRef] [PubMed]

54. Boisset, C.; Pétrequin, C.; Chanzy, H.; Henrissat, B.; Schülein, M. Optimized mixtures of recombinant humicola insolens cellulases for the biodegradation of crystalline cellulose. Biotechnol. Bioeng. 2001, 72, 339-345. [CrossRef]

55. Zhou, S.; Ingram, L.O. Synergistic hydrolysis of carboxymethyl cellulose and acid-swollen cellulose by two endoglucanases (celz and cely) fromerwinia chrysanthemi. J. Bacteriol. 2000, 182, 5676-5682. [CrossRef] [PubMed]

56. Boisset, C.; Fraschini, C.; Schülein, M.; Henrissat, B.; Chanzy, H. Imaging the enzymatic digestion of bacterial cellulose ribbons reveals the endo character of the cellobiohydrolase Cel6A from humicola insolens and its mode of synergy with cellobiohydrolase Cel7A. Appl. Environ. Microbiol. 2000, 66, 1444-1452. [CrossRef] [PubMed]

57. Väljamäe, P.; Sild, V.; Nutt, A.; Pettersson, G.; Johansson, G. Acid hydrolysis of bacterial cellulose reveals different modes of synergistic action between cellobiohydrolase I and endoglucanase I. Eur. J. Biochem. 1999, 266, 327-334. [CrossRef] [PubMed]

58. Fujita, Y.; Takahashi, S.; Ueda, M.; Tanaka, A.; Okada, H.; Morikawa, Y.; Kawaguchi, T.; Arai, M.; Fukuda, H.; Kondo, A. Direct and efficient production of ethanol from cellulosic material with a yeast strain displaying cellulolytic enzymes. Appl. Environ. Microbiol. 2002, 68, 5136-5141. [CrossRef] [PubMed]

59. Fujita, Y.; Ito, J.; Ueda, M.; Fukuda, H.; Kondo, A. Synergistic saccharification, and direct fermentation to ethanol, of amorphous cellulose by use of an engineered yeast strain codisplaying three types of cellulolytic enzyme. Appl. Environ. Microbiol. 2004, 70, 1207-1212. [CrossRef] [PubMed]

60. Kotaka, A.; Bando, H.; Kaya, M.; Kato-Murai, M.; Kuroda, K.; Sahara, H.; Hata, Y.; Kondo, A.; Ueda, M. Direct ethanol production from barley $\beta$-glucan by sake yeast displaying aspergillus oryzae $\beta$-glucosidase and endoglucanase. J. Biosci. Bioeng. 2008, 105, 622-627. [CrossRef] [PubMed]

61. Liu, Z.; Inokuma, K.; Ho, S.-H.; Haan, R.d.; Hasunuma, T.; Zyl, W.H.; Kondo, A. Combined cell-surface display- and secretion-based strategies for production of cellulosic ethanol with Saccharomyces cerevisiae. Biotechnol. Biofuels 2015, 8, 1-12. [CrossRef] [PubMed]

62. Liu, Z.; Ho, S.-H.; Sasaki, K.; den Haan, R.; Inokuma, K.; Ogino, C.; van Zyl, W.H.; Hasunuma, T.; Kondo, A. Engineering of a novel cellulose-adherent cellulolytic Saccharomyces cerevisiae for cellulosic biofuel production. Sci. Rep. 2016, 6, 24550. [CrossRef] [PubMed]

63. Liu, Z.; Ho, S.-H.; Hasunuma, T.; Chang, J.-S.; Ren, N.-Q.; Kondo, A. Recent advances in yeast cell-surface display technologies for waste biorefineries. Bioresour. Technol. 2016, 215, 324-333. [CrossRef] [PubMed]

64. Yamada, R.; Taniguchi, N.; Tanaka, T.; Ogino, C.; Fukuda, H.; Kondo, A. Cocktail delta-integration: A novel method to construct cellulolytic enzyme expression ratio-optimized yeast strains. Microb. Cell Fact. 2010, 9, 32. [CrossRef] [PubMed] 
65. Yamada, R.; Tanaka, T.; Ogino, C.; Fukuda, H.; Kondo, A. Novel strategy for yeast construction using $\delta$-integration and cell fusion to efficiently produce ethanol from raw starch. Appl. Microbiol. Biotechnol. 2010, 85, 1491-1498. [CrossRef] [PubMed]

66. Yamada, R.; Taniguchi, N.; Tanaka, T.; Ogino, C.; Fukuda, H.; Kondo, A. Direct ethanol production from cellulosic materials using a diploid strain of Saccharomyces cerevisiae with optimized cellulase expression. Biotechnol. Biofuels 2011, 4, 8. [CrossRef] [PubMed]

67. Apiwatanapiwat, W.; Murata, Y.; Kosugi, A.; Yamada, R.; Kondo, A.; Arai, T.; Rugthaworn, P.; Mori, Y. Direct ethanol production from cassava pulp using a surface-engineered yeast strain co-displaying two amylases, two cellulases, and $\beta$-glucosidase. Appl. Microbiol. Biotechnol. 2011, 90, 377-384. [CrossRef] [PubMed]

68. Yamada, R.; Nakatani, Y.; Ogino, C.; Kondo, A. Efficient direct ethanol production from cellulose by cellulase-and cellodextrin transporter-co-expressing Saccharomyces cerevisiae. AMB Express 2013, 3, 34. [CrossRef] [PubMed]

69. Liu, Z.; Inokuma, K.; Ho, S.-H.; den Haan, R.; van Zyl, W.H.; Hasunuma, T.; Kondo, A. Improvement of ethanol production from crystalline cellulose via optimizing cellulase ratios in cellulolytic Saccharomyces cerevisiae. Biotechnol. Bioeng. 2017, 114, 1201-1207. [CrossRef] [PubMed]

70. Ito, J.; Kosugi, A.; Tanaka, T.; Kuroda, K.; Shibasaki, S.; Ogino, C.; Ueda, M.; Fukuda, H.; Doi, R.H.; Kondo, A. Regulation of the display ratio of enzymes on the Saccharomyces cerevisiae cell surface by the immunoglobulin $\mathrm{g}$ and cellulosomal enzyme binding domains. Appl. Environ. Microbiol. 2009, 75, 4149-4154. [CrossRef] [PubMed]

71. Lilly, M.; Fierobe, H.-P.; Van Zyl, W.H.; Volschenk, H. Heterologous expression of a clostridium minicellulosome in Saccharomyces cerevisiae. FEMS Yeast Res. 2009, 9, 1236-1249. [CrossRef] [PubMed]

72. Tsai, S.-L.; Goyal, G.; Chen, W. Surface display of a functional minicellulosome by intracellular complementation using a synthetic yeast consortium and its application to cellulose hydrolysis and ethanol production. Appl. Environ. Microbiol. 2010, 76, 7514-7520. [CrossRef] [PubMed]

73. Wen, F.; Sun, J.; Zhao, H. Yeast surface display of trifunctional minicellulosomes for simultaneous saccharification and fermentation of cellulose to ethanol. Appl. Environ. Microbiol. 2010, 76, 1251-1260. [CrossRef] [PubMed]

74. Kim, S.; Baek, S.-H.; Lee, K.; Hahn, J.-S. Cellulosic ethanol production using a yeast consortium displaying a minicellulosome and $\beta$-glucosidase. Microb. Cell Fact. 2013, 12, 1-8. [CrossRef] [PubMed]

75. Fan, L.H.; Zhang, Z.J.; Yu, X.Y.; Xue, Y.X.; Tan, T.W. Self-surface assembly of cellulosomes with two miniscaffoldins on Saccharomyces cerevisiae for cellulosic ethanol production. Proc. Natl. Acad. Sci. USA 2012, 109, 13260-13265. [CrossRef] [PubMed]

76. Tsai, S.L.; DaSilva, N.A.; Chen, W. Functional display of complex cellulosomes on the yeast surface via adaptive assembly. ACS Synth. Biol. 2013, 2, 14-21. [CrossRef] [PubMed]

77. Fan, L.-H.; Zhang, Z.-J.; Mei, S.; Lu, Y.-Y.; Li, M.; Wang, Z.-Y.; Yang, J.-G.; Yang, S.-T.; Tan, T.-W. Engineering yeast with bifunctional minicellulosome and cellodextrin pathway for co-utilization of cellulose-mixed sugars. Biotechnol. Biofuels 2016, 9, 137. [CrossRef] [PubMed]

78. Belgacem, M.N.; Gandini, A. Monomers, Polymers and Composites from Renewable Resources; Elsevier Science: Amsterdam, The Netherlands, 2011.

79. Akpinar, O.; Erdogan, K.; Bostanci, S. Production of xylooligosaccharides by controlled acid hydrolysis of lignocellulosic materials. Carbohydr. Res. 2009, 344, 660-666. [CrossRef] [PubMed]

80. Moreira, L.R.S.; Filho, E.X.F. Insights into the mechanism of enzymatic hydrolysis of xylan. Appl. Microbiol. Biotechnol. 2016, 100, 5205-5214. [CrossRef] [PubMed]

81. Van Dyk, J.S.; Pletschke, B.I. Enzyme synergy for enhanced degradation of lignocellulosic waste. In Advances in Enzyme Biotechnology; Shukla, P., Pletschke, I.B., Eds.; Springer: New Delhi, India, 2013; pp. 57-65.

82. Vardakou, M.; Katapodis, P.; Topakas, E.; Kekos, D.; Macris, B.J.; Christakopoulos, P. Synergy between enzymes involved in the degradation of insoluble wheat flour arabinoxylan. Innov. Food Sci. Emerg. Technol. 2004, 5, 107-112. [CrossRef]

83. Sørensen, H.R.; Meyer, A.S.; Pedersen, S. Enzymatic hydrolysis of water-soluble wheat arabinoxylan. 1. Synergy between $\alpha$-L-arabinofuranosidases, endo-1,4- $\beta$-xylanases, and $\beta$-xylosidase activities. Biotechnol. Bioeng. 2003, 81, 726-731. [CrossRef] [PubMed] 
84. Sørensen, H.R.; Pedersen, S.; Viksø-Nielsen, A.; Meyer, A.S. Efficiencies of designed enzyme combinations in releasing arabinose and xylose from wheat arabinoxylan in an industrial ethanol fermentation residue. Enzyme Microb. Technol. 2005, 36, 773-784. [CrossRef]

85. Sørensen, H.R.; Pedersen, S.; Meyer, A.S. Synergistic enzyme mechanisms and effects of sequential enzyme additions on degradation of water insoluble wheat arabinoxylan. Enzyme Microb. Technol. 2007, 40, 908-918. [CrossRef]

86. Kovacs, K. Production of Cellulolytic Enzymes with Trichoderma Atroviride Mutants for the Biomass-to-Bioethanol Process; Lund University: Lund, Sweden, 2009.

87. Adelsberger, H.; Hertel, C.; Glawischnig, E.; Zverlov, V.V.; Schwarz, W.H. Enzyme system of clostridium stercorarium for hydrolysis of arabinoxylan: Reconstitution of the in vivo system from recombinant enzymes. Microbiology 2004, 150, 2257-2266. [CrossRef] [PubMed]

88. Selig, M.J.; Adney, W.S.; Himmel, M.E.; Decker, S.R. The impact of cell wall acetylation on corn stover hydrolysis by cellulolytic and xylanolytic enzymes. Cellulose 2009, 16, 711-722. [CrossRef]

89. De Vries, R.P.; Kester, H.C.M.; Poulsen, C.H.; Benen, J.A.E.; Visser, J. Synergy between enzymes from aspergillus involved in the degradation of plant cell wall polysaccharides. Carbohydr. Res. 2000, 327, 401-410. [CrossRef]

90. Ho, N.W.; Chen, Z.; Brainard, A.P. Genetically engineered saccharomyces yeast capable of effective cofermentation of glucose and xylose. Appl. Environ. Microbiol. 1998, 64, 1852-1859. [PubMed]

91. Kuyper, M.; Winkler, A.A.; van Dijken, J.P.; Pronk, J.T. Minimal metabolic engineering of Saccharomyces cerevisiae for efficient anaerobic xylose fermentation: A proof of principle. FEMS Yeast Res. 2004, 4, 655-664. [CrossRef] [PubMed]

92. Kuyper, M.; Harhangi, H.; Stave, A.; Winkler, A.; Jetten, M.; De-Laat, W.; Den-Ridder, J.; Op den Camp, H.; van Dijken, J.; Pronk, J. High-level functional expression of a fungal xylose isomerase: The key to efficient ethanolic fermentation of xylose by Saccharomyces cerevisiae? FEMS Yeast Res. 2003, 4, 69-78. [CrossRef]

93. Harhangi, H.; Akhmanova, A.; Emmens, R.; van der-Drift, C.; De-Laat, W.; Van-Dijken, J.; Jetten, M.; Pronk, J.; Op den Camp, H. Xylose metabolism in the anaerobic fungus Piromyces sp. Strain E2 follows the bacterial pathway. Arch. Microbiol. 2003, 180, 134-141. [CrossRef] [PubMed]

94. Karhumaa, K.; Garcia Sanchez, R.; Hahn-Hagerdal, B.; Gorwa-Grauslund, M. Comparison of the xylose reductase-xylitol dehydrogenase and the xylose isomerase pathways for xylose fermentation by recombinant Sacharomyces cerevisiae. Microb. Cell Fact. 2007, 6, 5. [CrossRef] [PubMed]

95. Katahira, S.; Fujita, Y.; Mizuike, A.; Fukuda, H.; Kondo, A. Construction of a xylan-fermenting yeast strain through codisplay of xylanolytic enzymes on the surface of xylose-utilizing Saccharomyces cerevisiae cells. Appl. Environ. Microbiol. 2004, 70, 5407-5414. [CrossRef] [PubMed]

96. Fujita, Y.; Katahira, S.; Ueda, M.; Tanaka, A.; Okada, H.; Morikawa, Y.; Fukuda, H.; Kondo, A. Construction of whole-cell biocatalyst for xylan degradation through cell-surface xylanase display in Saccharomyces cerevisiae. J. Mol. Catal. B Enzym. 2002, 17, 189-195. [CrossRef]

97. Malgas, S.; van Dyk, J.S.; Pletschke, B.I. A review of the enzymatic hydrolysis of mannans and synergistic interactions between $\beta$-mannanase, $\beta$-mannosidase and $\alpha$-galactosidase. World J. Microbiol. Biotechnol. 2015, 31, 1167-1175. [CrossRef] [PubMed]

98. Spivey, H.O.; Ovadi, J. Substrate channeling. Methods 1999, 19, 306-321. [CrossRef] [PubMed]

99. Sun, J.; Wen, F.; Si, T.; Xu, J.-H.; Zhao, H. Direct conversion of xylan to ethanol by recombinant Saccharomyces cerevisiae strains displaying an engineered minihemicellulosome. Appl. Environ. Microbiol. 2012, 78, 3837-3845. [CrossRef] [PubMed]

100. Wertz, J.L.; Bédué, O. Lignocellulosic Biorefineries; EFPL Press: Lausanne, Switzerland, 2013.

101. Harmsen, P.; Huijgen, W.; Bermudez, L.; Bakker, R. Literature Review of Physical and Chemical Pretreatment Processes for Lignocellulosic Biomass; 9085857570; Wageningen UR Food \& Biobased Research: Wageningen, The Netherlands, 2010.

102. Mosier, N.; Wyman, C.; Dale, B.; Elander, R.; Lee, Y.Y.; Holtzapple, M.; Ladisch, M. Features of promising technologies for pretreatment of lignocellulosic biomass. Bioresour. Technol. 2005, 96, 673-686. [CrossRef] [PubMed]

103. Matano, Y.; Hasunuma, T.; Kondo, A. Display of cellulases on the cell surface of Saccharomyces cerevisiae for high yield ethanol production from high-solid lignocellulosic biomass. Bioresour. Technol. 2012, 108, $128-133$. [CrossRef] [PubMed] 
104. Matano, Y.; Hasunuma, T.; Kondo, A. Cell recycle batch fermentation of high-solid lignocellulose using a recombinant cellulase-displaying yeast strain for high yield ethanol production in consolidated bioprocessing. Bioresour. Technol. 2013, 135, 403-409. [CrossRef] [PubMed]

105. Sakamoto, T.; Hasunuma, T.; Hori, Y.; Yamada, R.; Kondo, A. Direct ethanol production from hemicellulosic materials of rice straw by use of an engineered yeast strain codisplaying three types of hemicellulolytic enzymes on the surface of xylose-utilizing Saccharomyces cerevisiae cells. J. Biotechnol. 2012, 158, 203-210. [CrossRef] [PubMed]

106. Guirimand, G.; Sasaki, K.; Inokuma, K.; Bamba, T.; Hasunuma, T.; Kondo, A. Cell surface engineering of Saccharomyces cerevisiae combined with membrane separation technology for xylitol production from rice straw hydrolysate. Appl. Microbiol. Biotechnol. 2016, 100, 3477-3487. [CrossRef] [PubMed]

107. Katahira, S.; Mizuike, A.; Fukuda, H.; Kondo, A. Ethanol fermentation from lignocellulosic hydrolysate by a recombinant xylose- and cellooligosaccharide-assimilating yeast strain. Appl. Microbiol. Biotechnol. 2006, 72, 1136-1143. [CrossRef] [PubMed]

108. Haan, R.; Rensburg, E.; Rose, S.H.; Görgens, J.F.; Zyl, W.H. Progress and challenges in the engineering of non-cellulolytic microorganisms for consolidated bioprocessing. Curr. Opin. Biotechnol. 2015, 33, 32-38. [CrossRef] [PubMed]

109. Gao, G.; Mao, R.-Q.; Xiao, Y.; Zhou, J.; Liu, Y.-H.; Li, G. Efficient yeast cell-surface display of an endoglucanase of aspergillus flavus and functional characterization of the whole-cell enzyme. World J. Microbiol. Biotechnol. 2017, 33, 114. [CrossRef] [PubMed]

110. Yeasmin, S.; Kim, C.; Park, H.; Sheikh, M.; Lee, J.; Kim, J.; Back, K.; Kim, S. Cell surface display of cellulase activity-free xylanase enzyme on Saccharomyces cerevisiae EBY100. Appl. Biochem. Biotechnol. 2011, 164, 294-304. [CrossRef] [PubMed]

111. Fukuda, T.; Kato-Murai, M.; Kadonosono, T.; Sahara, H.; Hata, Y.; Suye, S.; Ueda, M. Enhancement of substrate recognition ability by combinatorial mutation of $\beta$-glucosidase displayed on the yeast cell surface. Appl. Microbiol. Biotechnol. 2007, 76, 1027-1033. [CrossRef] [PubMed]

112. Haan, R.; Kroukamp, H.; Zyl, J.H.-D.; Zyl, W.H. Cellobiohydrolase secretion by yeast: Current state and prospects for improvement. Process Biochem. 2013, 48, 1-12. [CrossRef]

113. Tang, H.; Song, M.; He, Y.; Wang, J.; Wang, S.; Shen, Y.; Hou, J.; Bao, X. Engineering vesicle trafficking improves the extracellular activity and surface display efficiency of cellulases in Saccharomyces cerevisiae. Biotechnol. Biofuels 2017, 10, 53. [CrossRef] [PubMed]

114. Kotaka, A.; Sahara, H.; Kuroda, K.; Kondo, A.; Ueda, M.; Hata, Y. Enhancement of $\beta$-glucosidase activity on the cell-surface of sake yeast by disruption of SED1. J. Biosci. Bioeng. 2010, 109, 442-446. [CrossRef] [PubMed]

115. Matsuoka, H.; Hashimoto, K.; Saijo, A.; Takada, Y.; Kondo, A.; Ueda, M.; Ooshima, H.; Tachibana, T.; Azuma, M. Cell wall structure suitable for surface display of proteins in Saccharomyces cerevisiae. Yeast 2014, 31, 67-76. [CrossRef] [PubMed]

116. Wentz, A.E.; Shusta, E.V. A novel high-throughput screen reveals yeast genes that increase secretion of heterologous proteins. Appl. Environ. Microbiol. 2007, 73, 1189-1198. [CrossRef] [PubMed]

117. Shuler, M.L.; Kargi, F. Bioprocess Engineering: Basic Concepts; Prentice Hall: Upper Saddle River, NJ, USA, 2002.

118. Özcan, S.; Johnston, M. Function and regulation of yeast hexose transporters. Microbiol. Mol. Biol. Rev. 1999, 63, 554-569. [PubMed]

119. André, B. An overview of membrane transport proteins in Saccharomyces cerevisiae. Yeast 1995, 11, $1575-1611$. [CrossRef] [PubMed]

120. Bisson, L.F.; Coons, D.M.; Kruckeberg, A.L.; Lewis, D.A. Yeast sugar transporters. Crit. Rev. Biochem. Mol. Biol. 1993, 28, 259-308. [CrossRef] [PubMed]

121. Wieczorke, R.; Krampe, S.; Weierstall, T.; Freidel, K.; Hollenberg, C.P.; Boles, E. Concurrent knock-out of at least 20 transporter genes is required to block uptake of hexoses in Saccharomyces cerevisiae. FEBS Lett. 1999, 464, 123-128. [CrossRef]

122. Solis-Escalante, D.; van den Broek, M.; Kuijpers, N.G.A.; Pronk, J.T.; Boles, E.; Daran, J.-M.; Daran-Lapujade, P. The genome sequence of the popular hexose-transport-deficient Saccharomyces cerevisiae strain EBY.Vw4000 reveals LoxP/Cre-induced translocations and gene loss. FEMS Yeast Res. 2015, 15. [CrossRef] [PubMed]

123. Hara, K.Y.; Kobayashi, J.; Yamada, R.; Sasaki, D.; Kuriya, Y.; Hirono-Hara, Y.; Ishii, J.; Araki, M.; Kondo, A. Transporter engineering in biomass utilization by yeast. FEMS Yeast Res. 2017, 17. [CrossRef] [PubMed] 
124. Kuijper, S.M. Engineering of Saccharomyces Cerevisiae for the Production of Fuel Ethanol from Xylose; Delft University of Technology: Delft, The Netherlands, 2006.

125. Kuyper, M.; Hartog, M.; Toirkens, M.; Almering, M.; Winkler, A.; Van-Dijken, J.; Pronk, J. Metabolic engineering of a xylose-isomerase-expressing Saccharomyces cerevisiae strain for rapid anaerobic xylose fermentation. FEMS Yeast Res. 2005, 5, 399-409. [CrossRef] [PubMed]

126. Lee, S.-M.; Jellison, T.; Alper, H. Systematic and evolutionary engineering of a xylose isomerase-based pathway in Saccharomyces cerevisiae for efficient conversion yields. Biotechnol. Biofuels 2014, 7, 1-8. [CrossRef] [PubMed]

127. Kim, S.R.; Skerker, J.M.; Kang, W.; Lesmana, A.; Wei, N.; Arkin, A.P.; Jin, Y.-S. Rational and evolutionary engineering approaches uncover a small set of genetic changes efficient for rapid xylose fermentation in Sacharomyces cerevisiae. PLoS ONE 2013, 8, e57048. [CrossRef] [PubMed]

128. Demeke, M.; Dietz, H.; Li, Y.; Foulquie-Moreno, M.; Mutturi, S.; Deprez, S.; Den Abt, T.; Bonini, B.; Liden, G.; Dumortier, F.; et al. Development of a D-xylose fermenting and inhibitor tolerant industrial Saccharomyces cerevisiae strain with high performance in lignocellulose hydrolysates using metabolic and evolutionary engineering. Biotechnol. Biofuels 2013, 6, 89. [CrossRef] [PubMed]

129. Zhou, H.; Cheng, J.; Wang, B.; Fink, G.; Stephanopoulos, G. Xylose isomerase overexpression along with engineering of the pentose phosphate pathway and evolutionary engineering enable rapid xylose utilization and ethanol production by Saccharomyces cerevisiae. Metab. Eng. 2012, 14, 611-622. [CrossRef] [PubMed]

130. Lee, S.-M.; Jellison, T.; Alper, H.S. Directed evolution of xylose isomerase for improved xylose catabolism and fermentation in the yeast Saccharomyces cerevisiae. Appl. Environ. Microbiol. 2012, 78, 5708-5716. [CrossRef] [PubMed]

131. Khatun, M.M.; Liu, C.-G.; Zhao, X.-Q.; Yuan, W.-J.; Bai, F.-W. Consolidated ethanol production from jerusalem artichoke tubers at elevated temperature by Saccharomyces cerevisiae engineered with inulinase expression through cell surface display. J. Ind. Microbiol. Biotechnol. 2017, 44, 295-301. [CrossRef] [PubMed]

132. Nakanishi, A.; Bae, J.G.; Fukai, K.; Tokumoto, N.; Kuroda, K.; Ogawa, J.; Nakatani, M.; Shimizu, S.; Ueda, M. Effect of pretreatment of hydrothermally processed rice straw with laccase-displaying yeast on ethanol fermentation. Appl. Microbiol. Biotechnol. 2012, 94, 939-948. [CrossRef] [PubMed]

133. Murai, T.; Ueda, M.; Kawaguchi, T.; Arai, M.; Tanaka, A. Assimilation of cellooligosaccharides by a cell surface-engineered yeast expressing $\beta$-glucosidase and carboxymethylcellulase from aspergillus aculeatus. Appl. Environ. Microbiol. 1998, 64, 4857-4861. [PubMed]

134. Murai, T.; Yoshino, T.; Ueda, M.; Haranoya, I.; Ashikari, T.; Yoshizumi, H.; Tanaka, A. Evaluation of the function of arming yeast displaying glucoamylase on its cell surface by direct fermentation of corn to ethanol. J. Ferment. Bioeng. 1998, 86, 569-572. [CrossRef]

135. Kotaka, A.; Sahara, H.; Hata, Y.; Abe, Y.; Kondo, A.; Kato-Murai, M.; Kuroda, K.; Ueda, M. Efficient and direct fermentation of starch to ethanol by sake yeast strains displaying fungal glucoamylases. Biosci. Biotechnol. Biochem. 2008, 72, 1376-1379. [CrossRef] [PubMed]

136. Inokuma, K.; Hasunuma, T.; Kondo, A. Efficient yeast cell-surface display of exo- and endo-cellulase using the SED1 anchoring region and its original promoter. Biotechnol. Biofuels 2014, 7, 1-11. [CrossRef] [PubMed]

137. Murai, T.; Ueda, M.; Yamamura, M.; Atomi, H.; Shibasaki, Y.; Kamasawa, N.; Osumi, M.; Amachi, T.; Tanaka, A. Construction of a starch-utilizing yeast by cell surface engineering. Appl. Environ. Microbiol. 1997, 63, 1362-1366. [PubMed]

(C) 2018 by the authors. Licensee MDPI, Basel, Switzerland. This article is an open access article distributed under the terms and conditions of the Creative Commons Attribution (CC BY) license (http:/ / creativecommons.org/licenses/by/4.0/). 